\title{
Leveraging Genetic Data to Elucidate the Relationship Between COVID-19 and Ischemic Stroke
}

\author{
Verena Zuber (D), PhD*; Alan Cameron DD, MBChB, PhD*; Evangelos P. Myserlis D, MD; Leonardo Bottolo (D), PhD; \\ Israel Fernandez-Cadenas (iD, PhD; Stephen Burgess (ID, PhD; Christopher D. Anderson (D), MD, MMSc; \\ Jesse Dawson, MD, MBChB; Dipender Gill (iD), BMBCh, PhD
}

BACKGROUND: The relationship between COVID-19 and ischemic stroke is poorly understood due to potential unmeasured confounding and reverse causation. We aimed to leverage genetic data to triangulate reported associations.

METHODS AND RESULTS: Analyses primarily focused on critical COVID-19, defined as hospitalization with COVID-19 requiring respiratory support or resulting in death. Cross-trait linkage disequilibrium score regression was used to estimate genetic correlations of critical COVID-19 with ischemic stroke, other related cardiovascular outcomes, and risk factors common to both COVID-19 and cardiovascular disease (body mass index, smoking and chronic inflammation, estimated using C-reactive protein). Mendelian randomization analysis was performed to investigate whether liability to critical COVID-19 was associated with increased risk of any cardiovascular outcome for which genetic correlation was identified. There was evidence of genetic correlation between critical COVID-19 and ischemic stroke $\left(r_{g}=0.29\right.$, false discovery rate [FDR] $\left.=0.012\right)$, body mass index $\left(r_{g}=0.21, F D R=0.00002\right)$, and C-reactive protein $\left(r_{g}=0.20\right.$, FDR=0.00035), but no other trait investigated. In Mendelian randomization, liability to critical COVID-19 was associated with increased risk of ischemic stroke (odds ratio [OR] per logOR increase in genetically predicted critical COVID-19 liability 1.03, 95\% Cl 1.00-1.06, $P$-value=0.03). Similar estimates were obtained for ischemic stroke subtypes. Consistent estimates were also obtained when performing statistical sensitivity analyses more robust to the inclusion of pleiotropic variants, including multivariable Mendelian randomization analyses adjusting for potential genetic confounding through body mass index, smoking, and chronic inflammation. There was no evidence to suggest that genetic liability to ischemic stroke increased the risk of critical COVID-19.

CONCLUSIONS: These data support that liability to critical COVID-19 is associated with an increased risk of ischemic stroke. The host response predisposing to severe COVID-19 is likely to increase the risk of ischemic stroke, independent of other potentially mitigating risk factors.

Key Words: COVID-19 a cross-trait linkage disequilibrium score regression $\boldsymbol{\|}$ ischemic stroke $\boldsymbol{\|}$ Mendelian randomization

(0) ARS-CoV-2 infection is the cause of the COVID-19 pandemic that has resulted in a health crisis of unprecedented magnitude., ${ }^{1,2}$ While much of the disease burden relates to respiratory failure and sepsis, some studies suggest an increased risk of ischemic stroke. ${ }^{3-6}$ This has been estimated to be seven times greater than in influenza infection, ${ }^{3}$ with up to $5 \%$ of people with severe COVID-19 suffering stroke. ${ }^{5}$ Strokes that occur in individuals with COVID-19 are more severe, have poorer outcomes, and higher mortality rates than in those without COVID-19, despite similar acute management. 6,7 Indeed, almost two-fifths of people

Correspondence to: Verena Zuber, Department of Epidemiology and Biostatistics, School of Public Health, Medical School Building, St Mary's Hospital, Imperial College London, UK, W2 1PG. E-mail: v.zuber@imperial.ac.uk

*V. Zuber and A. Cameron contributed equally to this article and are co-first authors.

Preprint posted on MedRxiv March 1, 2021. doi: https://doi.org/10.1101/2021.02.25.21252441.

Supplementary Material for this article is available at https://www.ahajournals.org/doi/suppl/10.1161/JAHA.121.022433

For Sources of Funding and Disclosures, see page 8.

(C) 2021 The Authors. Published on behalf of the American Heart Association, Inc., by Wiley. This is an open access article under the terms of the Creative Commons Attribution License, which permits use, distribution and reproduction in any medium, provided the original work is properly cited.

JAHA is available at: www. ahajournals.org/journal/jaha 


\section{CLINICAL PERSPECTIVE}

\section{What Is New?}

- This study identified evidence of genetic correlation between critical COVID-19 and ischemic stroke, body mass index and C-reactive protein.

- In Mendelian randomization, liability to critical COVID-19 was associated with increased risk of any ischemic stroke, with similar estimates obtained for ischemic stroke subtypes.

- There was no evidence to suggest that genetic liability to ischemic stroke increased the risk of critical COVID-19.

\section{What Are the Clinical Implications?}

- These data support that liability to critical COVID-19 is associated with an increased risk of ischemic stroke.

- The host response predisposing to severe COVID-19 is likely to increase the risk of ischemic stroke, independent of other potentially mitigating risk factors.

\section{Nonstandard Abbreviations and Acronyms}

$\begin{array}{ll}\text { Fdr } & \text { false discovery rate } \\ \text { IVW } & \text { inverse-variance weighted } \\ \text { LDSC } & \text { linkage disequilibrium score regression } \\ \text { MR } & \text { Mendelian randomization }\end{array}$

with COVID-19 who develop stroke consequently die. ${ }^{8}$ However, some studies do not support an increased risk of stroke in individuals with COVID-19., 9,10 Obtaining unbiased estimates for the risk of stroke in people with COVID-19 is challenging due to difficulty diagnosing mild COVID-19 and an overall reduction in the rate of admission to hospital with stroke, and minor stroke in particular, during the pandemic, ${ }^{9,11}$ Furthermore, observational studies investigating the association between COVID-19 and stroke are vulnerable to potential confounding and reverse causation. ${ }^{3-6}$ For example, there are common risk factors for severe COVID-19 and stroke, such as obesity and smoking. ${ }^{12}$ Similarly, patients with acute stroke have a dampened immune response and may be more susceptible to severe COVID-19.13

Leverage of genetic data can help overcome some of these issues. Cross-trait linkage disequilibrium score regression (LDSC) can be used to estimate the genetic correlation between traits. Mendelian randomization (MR) can be employed to investigate whether genetic variants predicting an exposure (such as COVID-19) also associate with risk of an outcome (such as ischemic stroke). ${ }^{14}$ There are numerous plausible mechanisms by which COVID-19 may be increasing ischemic stroke risk. COVID-19 can trigger a cytokine storm with upregulation of pro-inflammatory signaling and endothelial dysfunction that predisposes to a hypercoagulable state and can lead to thromboembolic events. ${ }^{15}$ Indeed, COVID-19 also appears to promote the development of other cardiovascular disorders including myocardial injury, myocardial ischemia, arrhythmias, heart failure, and venous thromboembolism. ${ }^{15}$ Furthermore, pre-existing cardiovascular disease (CVD) is associated with high mortality in people with COVID-19, which has raised the possibility of a bidirectional interaction between COVID-19 and the cardiovascular system. ${ }^{15} \mathrm{MR}$ analyses also can allow the exploration of such bidirectional relationships.

Elucidating the relationship between COVID-19 and risk of ischemic stroke could prove important for optimizing prevention and treatment strategies. With this in mind, we performed cross-trait LDSC to investigate whether there is a genetic correlation between COVID-19 and ischemic stroke, and followed this up with MR analyses to investigate whether any such statistically significant correlation might be explained by liability to COVID-19 being associated with increased risk of ischemic stroke.

\section{METHODS}

All genetic association data used in this work are publicly accessible. Appropriate patient consent and ethical approval had been obtained in the original studies from which they were obtained (Table S1). Statistical code related to the analyses performed in the current study is freely available from Github (https://github. com/verena-zuber/covid19_and_stroke).

\section{Study Overview}

First, we performed cross-trait LDSC to estimate genetic correlations for COVID-19 with ischemic stroke, other related CVDs, and risk factors common to both COVID-19 and CVD. Second, for CVD outcomes that showed evidence of genetic correlation with COVID-19, MR analysis was performed to investigate whether liability to COVID-19 was also associated with these outcomes. Finally, bidirectional MR was carried out to investigate potential reverse associations, ie whether genetic liability to the CVD outcome was also associated with increased risk of COVID-19. A graphical overview of the analysis plan is presented in Figure S1.

\section{Exposure Definitions and Genetic Association Estimates for COVID-19}

Genetic association estimates for COVID-19 were obtained from release 5 of the COVID-19 host genetics 
consortium. ${ }^{16,17}$ In our main analysis we focused on the most severe definition of COVID-19 available (referred to critical COVID-19 from here), where a critical case is defined as an individual who was hospitalized with laboratory confirmed SARS-CoV-2 infection and required respiratory support or died. Genetic associations were derived from 5101 cases and 1383241 controls from the general population. Hospital admission and requiring respiratory support or death is a proxy for disease severity and is preferred here over other case definitions which are solely based on a positive COVID-19 test result. Previous studies have shown that bias may impact analyses identifying cases based on likelihood of testing for SARS-CoV-2 infection, because participants being tested for SARS-CoV-2 infection are selected for a wide range of genetic, behavioral, and demographic traits. ${ }^{9}$

Results based on other COVID-19 definitions from the COVID-19 host genetics consortium were performed as further sensitivity analysis. As the first sensitivity analysis definition, we compared individuals with laboratory confirmed SARS-CoV-2 infection who had been hospitalized (cases) versus individuals with laboratory confirmed SARS-CoV-2 infection who did not require hospitalization (4829 cases and 11816 controls). As a second analysis sensitivity definition, we compared individuals with laboratory confirmed SARSCoV-2 infection who had been hospitalized (cases) versus the general population (9986 cases and 1877672 controls). The third sensitivity analysis definition was based on individuals with reported COVID-19 (laboratory confirmed, physician-reported or self-reported; cases) versus controls from the general population (38 984 cases and 1644784 controls). An overview of the COVID-19 definitions is given in Table S1.

\section{Outcomes Ischemic Stroke}

The primary outcome was any ischemic stroke (34 217 cases). In secondary hypothesis-generating analyses, stroke subtypes were further explored as large artery stroke (LAS, 4373 cases), cardioembolic stroke (CES, 7193 cases), and small vessel stroke (SVS, 5386 cases). ${ }^{18}$ The common control pool included 406111 individuals. Genetic association data were derived from the MEGASTROKE consortium. ${ }^{18}$

\section{Related CVD Outcomes}

We considered other CVD outcomes related to ischemic stroke in their pathophysiology. These were coronary artery disease (including myocardial infarction, acute coronary syndrome, chronic stable angina, or $>50 \%$ coronary artery stenosis), heart failure, and atrial fibrillation. Genetic associations with risk for coronary artery disease were measured on 60801 cases and 123504 controls and taken from the Coronary ARtery Dlsease Genome wide Replication and Meta-analysis (CARDIOGRAM) plus The Coronary Artery Disease (C4D) consortium (CARDloGRAMplusC4D), ${ }^{19}$ for heart failure were measured on 47309 cases and 930014 controls and taken from the HEart failuRe Molecular Epidemiology for therapeutic targetS (HERMES) consortium $^{20}$ and for atrial fibrillation were measured on 65446 cases and 522744 controls and taken from a transethnic meta-analysis. ${ }^{21}$

\section{Risk Factors Related to Both COVID-19 and CVD}

To investigate whether any genetic correlation between critical COVID-19 and the CVD outcomes was related to confounding factors, we further considered common risk factors to both, including obesity, smoking, and chronic inflammation. ${ }^{22-25}$ Genetic association estimates to proxy these traits were taken from a genome-wide association study (GWAS) on body mass index (BMI) measured on 694649 subjects, ${ }^{26}$ lifetime smoking index measured on 462690 subjects, ${ }^{27}$ and CRP (C-reactive protein) measured on 361194 individuals in UK Biobank. ${ }^{28}$

\section{Statistical Analysis Cross-Trait Linkage Disequilibrium Score Regression}

We performed LDSC to estimate the genetic correlation $\left(r_{g}\right)$ of critical COVID-19 with the primary outcome ischemic stroke, and secondary outcomes coronary artery disease, heart failure, and atrial fibrillation, using GWAS summary statistics data. ${ }^{29}$ We also estimated correlation with possible genetic confounders, including BMI, lifetime smoking index, and CRP. We restricted our analyses to HapMap 3 single-nucleotide polymorphisms (SNPs), which are known to be well-imputed across most studies and utilized the pre-computed European LD-scores estimated using the 1000G reference panel, provided by the LDSC creators. For each set of summary statistics, the SNP-specific sample size information was used. If not available, we assumed that all SNPs had the same sample size for that trait, defined as the total sample size for continuous phenotypes or as the sum of cases and controls for case/control phenotypes. By default, LDSC also removed variants that were duplicate, strand-ambiguous, not SNPs (eg indels), with $P$-values not between 0 and 1 , with alleles that did not match with the $1000 \mathrm{G}$ reference panel, and with low effective sample size or not included in all studies of a GWAS meta-analysis (if such information was available) for traits with no effective sample size 
information. After estimation of the genetic correlation across all phenotypes, we corrected for multiple hypothesis testing using the Benjamini and Yekutieli false discovery rate (FDR). ${ }^{30}$ FDR-corrected $P$-values $<0.05$ were considered statistically significant.

\section{Mendelian Randomization Analyses}

Genetic Variants Used as Instrumental Variables

Genetic variants were selected based on associations with critical COVID-19. In our main analysis, we selected uncorrelated genetic variants (clumped at correlation threshold $\left.r^{2}<0.01\right)$ at $P$-value $<5 \times 10^{-6}$. In sensitivity analyses, we applied a more stringent threshold and considered only genome-wide significant genetic variants $\left(P\right.$-value $\left.<5 \times 10^{-8}\right)$.

Main Analysis

For CVD outcomes that showed evidence of genetic correlation with critical COVID-19 in LDSC, MR analysis was performed to estimate the association of genetically predicted liability to critical COVID-19 with that outcome using the random effects 2-sample inverse-variance weighted (IVW) method. ${ }^{31}$ The IVW estimate can be biased by pleiotropy when a genetic variant associates the outcome (eg, ischemic stroke) via a pathway other than through the exposure (ie, liability to critical COVID-19). Pleiotropy can cause heterogeneity in the MR estimates obtained by different variants employed as instruments, which was assessed using the $Q$-statistic and the respective heterogeneity $P$-value. ${ }^{32} \mathrm{~A}$ Mendelian randomization estimate with $P$-value $<0.05$ for the main IVW analysis was deemed to represent supportive evidence, given that MR was only performed to follow up positive LDSC findings.

Sensitivity Analyses-Robust Methods

We performed sensitivity analyses with pleiotropyrobust two-sample summary-level MR approaches, including the weighted median $\mathrm{MR}^{33}$ and MR-Egger ${ }^{34}$ to compare the MR estimates between different MR models. Each of these methods provides a statistically consistent estimator of the true causal estimate under different assumptions. The intercept of the MR-Egger model represents a test for directional pleiotropy and we included this in sensitivity analyses. ${ }^{35}$

Pleiotropic Pathways-Inflammation and Cardiometabolic Risk

Factors

We further performed multivariable MR to adjust for potential pleiotropic pathways via cardiometabolic risk factors that are known to affect risk of both COVID-19 and CVD12, including obesity (BMI), ${ }^{26}$ lifetime smoking index, ${ }^{27}$ and chronic inflammation (estimated using
CRP). Multivariable MR includes all the respective genetic associations in a joint model to account for genetic confounding. ${ }^{36}$ While univariable MR measures the total estimate of an exposure, multivariable MR measures the direct estimate of the exposure independent of other risk factors (ie, pleiotropy or genetic confounders) in the model. ${ }^{37}$ In the multivariable MR model, we selected instruments based on the primary exposure of critical COVID-19. We compared the multivariable MR model with the univariable MR model using likelihood ratio test to evaluate if accounting for the pleiotropic pathway provides a better model fit than the univariable MR model.

\section{Bidirectional MR}

For CVD outcomes that showed evidence of genetic correlation with critical COVID-19 in LDSC, bidirectional MR was also performed to investigate for any association of genetic liability to that CVD outcome with risk of critical COVID-19. Uncorrelated genetic variants $\left(r^{2}<0.01\right)$ associated with the CVD outcome at a $P$-value $<5 \times 10^{-6}$ were selected as instruments.

\section{Power Calculation}

Power to detect an association of genetically proxied liability to critical COVID-19 with all-cause ischemic stroke and its subtypes was assessed using power calculations for MR. ${ }^{38}$ Sample sizes were set according to the number of cases and controls in the MEGASTROKE consortium as given in Table S1. Heritability of the exposure was calculated from the $F$-statistic of the genetic variants selected as instrumental variables, which was approximated using the squared regression coefficient divided by its squared standard error. The F-statistic was then transformed to the proportion of variance in the phenotype explained by the genetic variants $R^{2}$ using the Cragg-Donald transformation. ${ }^{39}$

MR estimates are expressed as odds ratios (OR) per unit increase in the logOR of the exposure for binary traits. All analyses were performed using the ieugwasr (version 0.1.5) and MendelianRandomization (version 0.5.0) R packages. ${ }^{40}$

\section{RESULTS}

\section{LD Score Regression}

Performing LDSC, we found evidence of genetic correlation between critical COVID-19 and ischemic stroke $\left(r_{g}=0.29\right.$, FDR- $P$-value $\left.=0.012\right)$ (Figure 1). Critical COVID-19 was also genetically correlated with BMI $\left(r_{g}=0.21\right.$, FDR- $P$-value $\left.=0.00002\right)$ and CRP $\left(r_{g}=0.20\right.$, FDR- $P$-value $=0.00035)$. We did not observe evidence for genetic correlation between critical COVID-19 and the CVD outcomes (Table S2), and therefore focused 
the consequent MR analysis only on ischemic stroke and its subtypes.

\section{Mendelian Randomization}

We selected 31 uncorrelated genetic variants as instrumental variables for liability to critical COVID-19. These are detailed in Table S3, along with their associations with ischemic stroke and its subtypes. MR estimates are presented in Figure 2. In a univariable MR analysis, genetically proxied liability to critical COVID-19 was associated with all-cause ischemic stroke (OR 1.03, 95\% $\mathrm{Cl} 1.00$ to $1.06, P$-value $=0.03)$. Restricting to ischemic stroke subtypes, there were similar MR estimates for cardioembolic stroke (OR 1.06, 95\% Cl 1.01 to 1.12, $P$ value $=0.03$ ), large artery stroke (OR $1.07,95 \% \mathrm{Cl} 1.00$ to $1.14, P$-value $=0.06$ ) and small-vessel stroke (OR $1.05,95 \% \mathrm{Cl} 1.00$ to $1.11, P$-value=0.06). Power calculations shown in Figure S2 supported lower power for ischemic stroke subtypes compared to all-cause ischemic stroke. For the MR estimates generated by different variants, we observed heterogeneity greater than would be expected by chance only for cardioembolic stroke (heterogeneity $P$-value $=0.049$ ), but none of the other considered ischemic stroke categories.

\section{Mendelian Randomization Sensitivity Analyses} are presented in Figure S3. We observed consistent MR estimates for ischemic stroke risk in sensitivity analyses based on pleiotropy-robust approaches as in the main analysis and none of the intercept estimates of MR-Egger suggested directional pleiotropy (Table S4). In multivariable MR to investigate potential pleiotropy through risk factors common to both COVID-19 and $C V D$, there was little evidence for attenuation of the size of the estimate in any of these analyses (Figure S4), which was confirmed by likelihood ratio test (Table S5).

\section{Sensitivity Analysis Based on Genome- Wide Significant Genetic Variants}

As an additional sensitivity analysis, we used a more stringent $P$-value threshold based on genome-wide significance to select genetic variants as instrumental variables. We identified 9 uncorrelated genetic variants that associated with critical COVID-19 at genome-wide significance ( $P$-value $\left.<5 \times 10^{-8}\right)$. This MR analysis based on fewer variants generated consistent estimates to the main analysis, but with wider Cls that crossed the null, reflective of lower statistical power. Results are displayed in Figure S5.

\section{Comparison With Other COVID-19 Definitions}

We further considered other COVID-19 definitions (Figure S6 and Table S6). Genetically predicted COVID-19 requiring hospitalization as compared to not requiring hospitalization was associated with increased risk of any ischemic stroke (OR 1.05, 95\% Cl 1.01 to 1.10, $P$-value=0.01) and small-vessel stroke (OR 1.22,

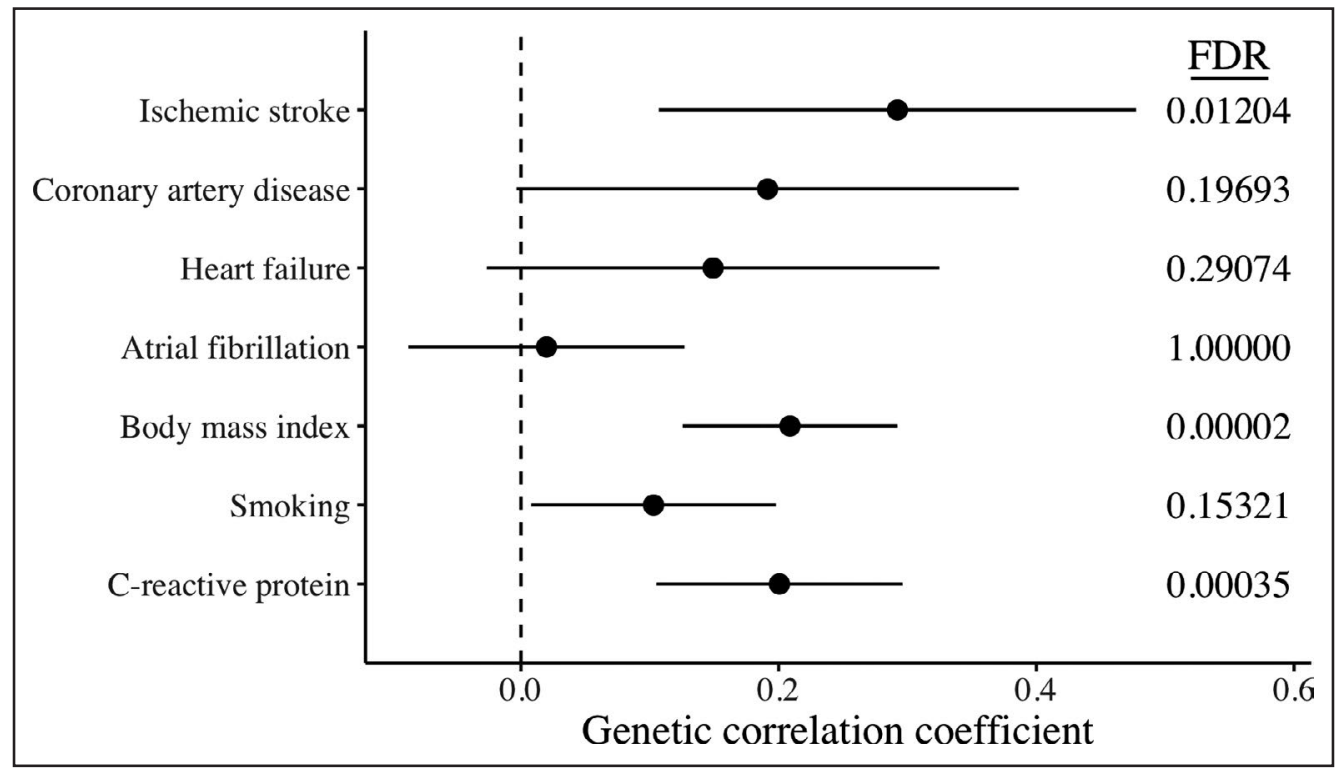

Figure 1. Genetic correlation coefficient ( $x$-axis) with $95 \% \mathrm{Cl}$ for critical COVID-19 and ischemic stroke, related cardiovascular disease outcomes, and risk factors for both COVID-19 and cardiovascular disease ( $y$-axis), estimated by cross-trait linkage disequilibrium score regression. Multiple testing adjustment using the Benjamini and Yekutieli false discovery rate (FDR) are given on the right. 


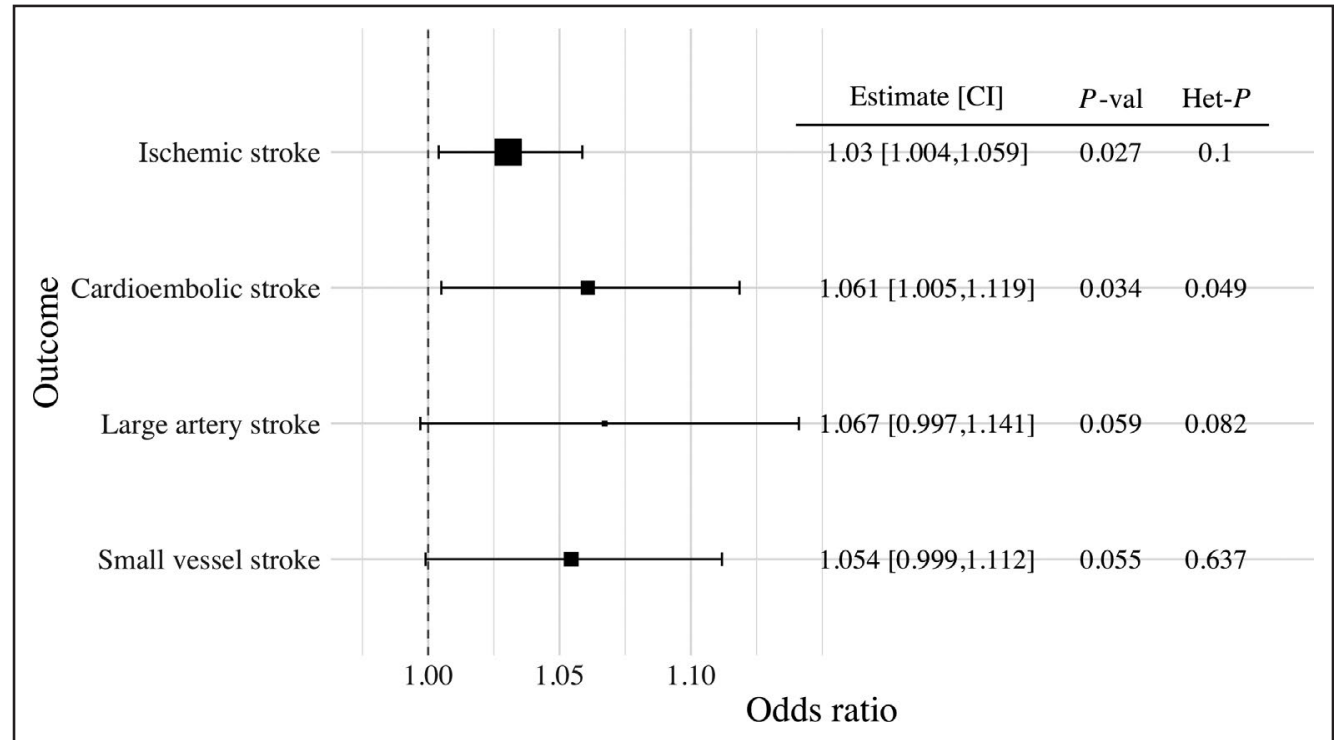

Figure 2. Forest plot illustrating the Mendelian randomization estimates of liability to critical COVID-19 with stroke outcomes based on inverse-variance weighted Mendelian randomization using genetic variants that were associated with critical COVID-19 at a $P$-value level of $5 \times 10^{-6}$ or smaller.

Mendelian randomization estimates represent the odds ratio of ischemic stroke outcomes per unit increase in the log-odds ratio of liability to critical COVID-19. Additional columns include the Mendelian randomization estimate, its $95 \% \mathrm{Cl}$, the $P$-value of the inverse-variance weighted Mendelian randomization estimate to be different from $1(P$-val), and heterogeneity measured by the $Q$-statistic and the respective heterogeneity $P$-value (Het- $P$ ). Outcomes included any ischemic stroke, cardioembolic stroke, large artery stroke, and small vessel stroke.

95\% Cl 1.11 to $1.34, P$-value $=0.000055)$. Considering reported COVID-19 (laboratory confirmed, physicianreported or self-reported) versus controls from the general population, this was associated with increased risk of any ischemic stroke (OR $1.13,95 \% \mathrm{Cl} 1.01$ to 1.26, $P$-value $=0.04)$ and large artery stroke (OR 1.46, $95 \% \mathrm{Cl} 1.18$ to $1.81, P$-value $=0.00042)$.

\section{Bidirectional MR}

There was no strong evidence to support that genetic liability to any of the considered ischemic stroke outcomes was associated with increased risk of critical COVID-19, as illustrated in Figure 3.

\section{DISCUSSION}

In this study, we used cross-trait LDSC to explore the genetic correlation of critical COVID-19 with ischemic stroke, other CVD outcomes, and risk factors common to both. We identified a genetic correlation between critical COVID-19 and ischemic stroke, and performed MR analyses that found genetic liability to critical COVID-19 to be associated with increased risk of ischemic stroke. Notably, there was no evidence to support that these associations were attributable to shared risk factors, such as obesity, smoking, and chronic inflammation. Furthermore, there was no MR evidence that genetic liability to ischemic stroke increases risk of critical COVID-19.

When we considered critical COVID-19 and ischemic stroke subtypes, only cardioembolic stroke remained statistically significant. There are 2 main possible explanations for this observation. The first is that there are pathophysiological differences across stroke subtypes. Indeed, it is conceivable that the host response to critical COVID-19 may be more likely to culminate in cardioembolic stroke through an acute, pro-inflammatory, hypercoagulable state that results in cardiac thromboembolism; as opposed to occlusion of small penetrating cerebral arteries and small vessel strokes which are generally a result of more longstanding conditions such as hypertension or diabetes. ${ }^{41}$ The second possible explanation is that smaller sample sizes for each stroke subtype compared to any ischemic stroke may mean that we were unable to detect a statistically significance difference in stroke subtypes due to reduced power as shown in Figure S2. This explanation would be supported by similar point estimates to any ischemic stroke across stroke subtypes.

To date, studies assessing the incidence of ischemic stroke during the COVID-19 pandemic have 


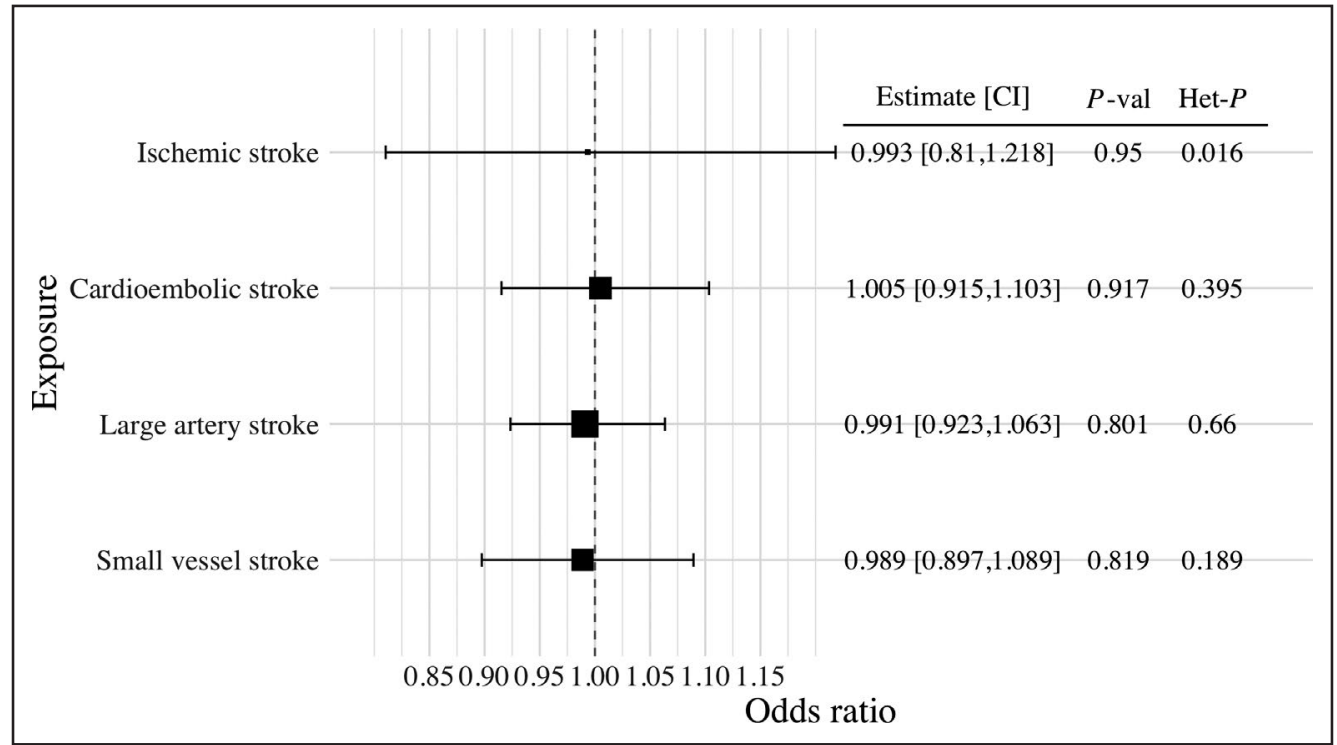

Figure 3. Forest plot of the bidirectional Mendelian randomization analysis illustrating the inverse-variance weighted Mendelian randomization estimate of liability to stroke phenotypes with critical COVID-19.

Genetic variants which were associated with the stroke phenotypes were selected as instrumental variables at a $P$-value level of $5 \times 10^{-6}$ or smaller. Mendelian randomization estimates represent the odds ratio of critical COVID-19 per unit increase in the log odds ratio of stroke phenotype. Additional columns include the Mendelian randomization estimate, its $95 \% \mathrm{Cl}$, the $P$-value of the inverse-variance weighted Mendelian randomization estimate to be different from 1 ( $P$-val), and heterogeneity measured by the $Q$-statistic and the respective heterogeneity $P$-value (Het- $P$ ). Exposures included any ischemic stroke, cardioembolic stroke, large artery stroke, and small vessel stroke.

produced contrasting findings. It has also been uncertain whether any association between COVID-19 and ischemic stroke is due to a direct effect of SARSCoV-2 viral infection, the host response in COVID-19, or both. On one hand, some studies demonstrate that the likelihood of stroke is 7-fold higher in people with COVID-19 than with influenza, ${ }^{3}$ that COVID-19 is associated with 21-fold increased odds of in-hospital stroke compared to patients without COVID-19, ${ }^{6}$ and that stroke is the most common neurological/neuropsychiatric complication of COVID-19.4 On the contrary, other studies have demonstrated a reduced rate of hospital admissions with stroke during the first wave of the pandemic compared to one year before. ${ }^{9}$ Two main hypotheses have been proposed as explanations for these contrasting findings. The first is that the incidence of stroke declined during the first wave of the pandemic and that COVID-19 is not mechanistically associated with stroke, and the second is that the observed reduction in stroke presentations was due to a higher proportion of people with mild strokes not reaching stroke services. ${ }^{11,42}$

We have leveraged large-scale genetic data to address this and find that liability to critical COVID-19 is associated with increased risk of ischemic stroke. Moreover, our results are consistent with the hypothesis that it is the host response in COVID-19 which contributes to increased ischemic stroke risk. However, it is also important to note that our study design cannot directly inform on whether the SARSCoV-2 virus itself also be increases ischemic stroke risk, irrespective of the host inflammatory response. Mechanisms that increase risk of ischemic stroke in patients with COVID-19 are complex, ${ }^{5,15}$ and include systemic inflammation and endotheliopathy. ${ }^{15,43-45}$ COVID-19 can trigger a cytokine storm with upregulation of pro-inflammatory cytokines and chemokines such as tumor necrosis factor-a (TNF-a), interleukin-1 (IL-1) and IL-615. Endothelial inflammation can induce a microvascular and macrovascular endotheliopathy that contributes to a pro-thrombotic state. ${ }^{15,43}$

While prophylactic low molecular weight heparin is used to prevent thromboembolism in patients with COVID-19, more targeted approaches to prevent strokes are yet undefined. 5,46 Moreover, the REMAP-CAP (A Randomised, Embedded, Multifactorial, Adaptive Platform Trial for CommunityAcquired Pneumonia), ACTIV-4 (Anti-thrombotics for Adults Hospitalized With COVID-19), and ATTACC (Antithrombotic Therapy to Ameliorate Complications of COVID-19) trials have recently reported that therapeutic doses of anticoagulation do not improve clinical outcome and may increase bleeding for people with COVID-19 in the critical care setting. Previous work 
using an MR approach anticipated a beneficial effect of IL-6 receptor inhibition on both risk of ischemic stroke and severe COVID-19. ${ }^{47,48}$ More recently, clinical trials have demonstrated that IL-6 receptor inhibition can improve outcomes in patients hospitalized with COVID-19.49 Targeting the deleterious host immune response through similar approaches may also help to reduce the risk of ischemic stroke and should be further evaluated.

Our findings also support the hypothesis that few patients with minor strokes reached stroke services during the first wave of the COVID-19 pandemic. ${ }^{11}$ This is reinforced by data that demonstrate the reduction in stroke admissions observed in some centers during the first wave of the pandemic was driven mainly by a reduction in presentations with minor stroke syndromes. ${ }^{11}$ People with minor stroke are at high risk of early recurrence ${ }^{50}$ and public health messaging should encourage people to attend stroke services if they have any symptom of stroke during the COVID-19 pandemic.

We did not observe genetic correlation between critical COVID-19 and other CVD outcomes such as coronary heart disease, heart failure or atrial fibrillation. Other studies have reported acute coronary syndrome, heart failure, and arrhythmia in people with COVID-19. ${ }^{15}$ There are a number of possible explanations for these findings, which at first may appear discordant. First, myocardial injury and myocarditis may be a more common cardiac manifestation of COVID-19 than coronary artery plaque rupture and thrombosis. Second, the pulmonary oedema that is observed in people with critical COVID-19 is usually accompanied by acute respiratory distress syndrome and is mainly regarded as non-cardiogenic. ${ }^{15}$ Third, while arrhythmias are common manifestations of COVID-19, these may be triggered by acute myocardial injury and systemic factors (such as fever, sepsis, hypoxia, and electrolyte imbalance), rather than atrial fibrillation due to a chronic atrial cardiopathy, which is more likely to make up cases in the pre-pandemic atrial fibrillation GWAS. ${ }^{20}$

Our current study has strengths. We have made efficient use of existing large-scale data resources to address an important clinical issue in the context of the rapidly evolving global pandemic. A key strength of MR analysis is the use of randomly allocated genetic variants to help overcome environmental confounding, which is analogous to randomization of treatment allocation in clinical trials. This has helped to overcome some of the limitations of previous observational studies (either retrospective or cross-sectional) assessing the relationship between COVID-19 and ischemic stroke. ${ }^{3-6}$

Our work also has limitations. A series of modelling assumptions are made when using MR, in particular, that the genetic variants do not affect the considered outcomes through pathways independent of the exposure. While this can never be completely excluded, we employed methods that are robust to genetic confounding (pleiotropy) in a series of sensitivity analyses (including pleiotropy-robust MR methods and accounting for measured pleiotropy using multivariable $\mathrm{MR}$ ) and the estimates were consistent with our main analyses. We cannot be certain that genetic associations with liability to critical COVID-19 accurately reflect the pathophysiological process that actually occurs during critical COVID-19. For example, while genetic predisposition may place an individual at increased liability to critical COVID-19, it is not possible to determine from our analyses whether that factor is involved in the pathophysiological response to COVID-19.

In conclusion, we have found genetic evidence that liability to critical COVID-19 is associated with increased risk of ischemic stroke. Our results are consistent with the host response in critical COVID-19 underlying this relationship, and support the evaluation of strategies to mitigate this.

\section{ARTICLE INFORMATION}

Received May 11, 2021; accepted September 23, 2021

\section{Affiliations}

Department of Epidemiology and Biostatistics, School of Public Health, Imperial College London, London, UK (V.Z., D.G.); Dementia Research Institute at Imperial College London, London, UK (V.Z.); Institute of Cardiovascular and Medical Sciences, University of Glasgow, UK (A.C., J.D.); Center for Genomic Medicine (E.P.M.); and McCance Center for Brain Health (E.P.M., C.D.A.), Massachusetts General Hospital, Boston, MA; Program in Medical and Population Genetics, Broad Institute of MIT and Harvard, Cambridge, MA (E.P.M., C.D.A.); Department of Medical Genetics, School of Clinical Medicine, University of Cambridge, UK (L.B.); The Alan Turing Institute, London, UK (L.B.); Medical Research Council Biostatistics Unit, University of Cambridge, UK (L.B., S.B.); Stroke Pharmacogenomics and Genetics Group, Biomedical Research Institute, Sant Pau, Spain (I.F.); Department of Public Health and Primary Care, Cardiovascular Epidemiology Unit, University of Cambridge, UK (S.B.); Department of Neurology, Brigham and Women's Hospital, Boston, MA (C.D.A.); Clinical Pharmacology and Therapeutics Section, Institute of Medical and Biomedical Education and Institute for Infection and Immunity, St George's, University of London, London, UK (D.G.); Clinical Pharmacology Group, Pharmacy and Medicines Directorate, St George's University Hospitals NHS Foundation Trust, London, UK (D.G.); and Novo Nordisk Research Centre Oxford, , Oxford, UK (D.G.)

\section{Acknowledgments}

This work is dedicated to the memory of Maria Mion who died from COVID-19 related complications. Leonardo Bottolo is very grateful to the doctors, nurses, and staff of the Ospedale di Oderzo (TV, Italy) for the high standard of care for his mother.

\section{Sources of Funding}

VZ is supported by UK Dementia Research Institute at Imperial College London, which is funded by the Medical Research Council, Alzheimer's Society and Alzheimer's Research UK (MC_PC_17114). The research leading to these results has been conducted as part of the COVIRNA project (grant agreement $n^{\circ} 101016072$ ) funded by the European Union's Horizon 2020 Framework Programme for Research and Innovation. EPM is supported by the National Institutes of Health of the United States (R01NS103924, U01NS069763). LB acknowledges the MRC grant MR/S02638X/1, The BHF-Turing Cardiovascular Data Science Awards 2017 and The Alan Turing Institute under the Engineering and Physical Sciences Research Council grant EP/N510129/1. IF-C is supported by Inmungen-Cov2 project, Centro Superior de Investigaciones Científicas (CSIC). SB is supported by a Sir 
Henry Dale Fellowship jointly funded by the Wellcome Trust and the Royal Society (204623/Z/16/Z). This research was supported by the UKRI Medical Research Council [MC_UU_00002/7] and the NIHR Cambridge Biomedical Research Centre (BRC-1215-20014). The views expressed are those of the author(s) and not necessarily those of the NIHR or the Department of Health and Social Care. CDA is supported by the National Institutes of Health of the United States (R01NS103924, U01NS069763). DG is supported by the British Heart Foundation Centre of Research Excellence at Imperial College London (RE/18/4/34215) and by a National Institute for Health Research Clinical Lectureship at St. George's, University of London (CL-2020-16-001). This research was funded in part by the Wellcome Trust.

\section{Disclosures}

CDA receives sponsored research support from the American Heart Association, Massachusetts General Hospital, and Bayer AG, and has consulted for ApoPharma, Inc. DG is employed part-time by Novo Nordisk. The remaining authors have no disclosures to report.

\section{Supplementary Material}

Table S1-S6

Figure S1-S6

\section{REFERENCES}

1. Carter P, Anderson M, Mossialos E. Health system, public health, and economic implications of managing COVID-19 from a cardiovascular perspective. Eur Heart J. 2020;41:2516-2518. doi: 10.1093/eurheartj/ ehaa342.

2. Clerkin KJ, Fried JA, Raikhelkar J, Sayer G, Griffin JM, Masoumi A, Jain SS, Burkhoff D, Kumaraiah D, Rabbani L, et al. COVID-19 and cardiovascular disease. Circulation. 2020;141:1648-1655. doi: 10.1161/CIRCU LATIONAHA.120.046941

3. Merkler AE, Parikh NS, Mir S, Gupta A, Kamel H, Lin E, Lantos J, Schenck EJ, Goyal P, Bruce SS, et al. Risk of ischemic stroke in patients with Coronavirus Disease 2019 (COVID-19) vs patients with influenza. JAMA Neurol. 2020;77:1-7. doi: 10.1001/jamaneurol.2020.2730

4. Varatharaj A, Thomas N, Ellul MA, Davies NWS, Pollak TA, Tenorio EL, Sultan M, Easton A, Breen G, Zandi M, et al. Neurological and neuropsychiatric complications of COVID-19 in 153 patients: a UK-wide surveillance study. Lancet Psychiatry. 2020;7:875-882. doi: 10.1016/S2215 -0366(20)30287-X

5. Qureshi Al, Abd-Allah F, Al-Senani F, Aytac E, Borhani-Haghighi A, Ciccone A, Gomez CR, Gurkas E, Hsu CY, Jani V, et al. Management of acute ischemic stroke in patients with COVID-19 infection: report of an international panel. Int J Stroke. 2020;15:540-554. doi: 10.1177/17474 93020923234

6. Katz JM, Libman RB, Wang JJ, Sanelli P, Filippi CG, Gribko M, Pacia SV, Kuzniecky RI, Najjar S, Azhar S. Cerebrovascular complications of COVID-19. Stroke. 2020;51:e227-e231. doi: 10.1161/STROK EAHA.120.031265

7. Fuentes $\mathrm{B}$, Alonso de Leciñana $\mathrm{M}$, García-Madrona S, Díaz-Otero F, Aguirre C, Calleja P, Egido JA, Carneado-Ruiz J, Ruiz-Ares G, Rodríguez-Pardo J, et al. Stroke acute management and outcomes during the COVID-19 outbreak. Stroke. 2021;52:552-562. doi: 10.1161/ STROKEAHA.120.031769

8. Li Y, Li M, Wang M, Zhou Y, Chang J, Xian Y, Wang D, Mao L, Jin H, Hu B. Acute cerebrovascular disease following COVID-19: a single center, retrospective, observational study. Stroke Vasc Neurol. 2020;5:279284. doi: 10.1136/svn-2020-000431

9. Sacco S, Ricci S, Ornello R, Eusebi P, Petraglia L, Toni D, Rota E, Bruzzone G, Testa L, Bongioanni R, et al. Reduced admissions for cerebrovascular events during COVID-19 outbreak in Italy. Stroke. 2020:51:3746-3750. doi: 10.1161/STROKEAHA.120.031293

10. Qureshi Al, Baskett WI, Huang W, Shyu D, Myers D, Raju M, Lobanova I, Suri MFK, Naqvi SH, French BR, et al. Acute ischemic stroke and COVID-19: an analysis of 27676 patients. Stroke. 2021;52:905-912. doi: 10.1161/STROKEAHA.120.031786

11. Perry R, Banaras A, Werring DJ, Simister R. What has caused the fall in stroke admissions during the COVID-19 pandemic? I Neurol, 2020;267:3457-3458. doi: 10.1007/s00415-020-10030-2

12. Ponsford MJ, Gkatzionis A, Walker VM, Grant AJ, Wootton RE, Moore LSP, Fatumo S, Mason AM, Zuber V, Willer C, et al. Cardiometabolic traits, sepsis, and severe COVID-19: a Mendelian randomization investigation. Circulation. 2020;142:1791-1793. doi: 10.1161/CIRCULATIO NAHA.120.050753

13. Shi K, Wood K, Shi F-D, Wang X, Liu Q. Stroke-induced immunosuppression and poststroke infection. Stroke Vasc Neurol. 2018;3:34-41. doi: 10.1136/svn-2017-000123

14. Didelez V, Sheehan N. Mendelian randomization as an instrumental variable approach to causal inference. Stat Methods Med Res. 2007;16:309-330. doi: 10.1177/0962280206077743

15. Nishiga M, Wang DW, Han Y, Lewis DB, Wu JC. COVID-19 and cardiovascular disease: from basic mechanisms to clinical perspectives. Nat Rev Cardiol. 2020;17:543-558. doi: 10.1038/s41569-020-0413-9

16. COVID-19 Host Genetics Initiative. A global initiative to elucidate the role of host genetic factors in susceptibility and severity of the SARS-CoV-2 virus pandemic. Eur J Hum Genet. 2020;28:715-718. doi: 10.1038/ s41431-020-0636-6

17. COVID-19 Host Genetics Initiative. Mapping the human genetic architecture of COVID-19. Nature. 2021. doi: 10.1038/s41586-021-03767-x

18. Malik R, Chauhan G, Traylor M, Sargurupremraj M, Okada Y, Mishra A, Rutten-Jacobs L, Giese A-K, van der Laan SW, Gretarsdottir S, et al. Multiancestry genome-wide association study of 520,000 subjects identifies 32 loci associated with stroke and stroke subtypes. Nat Genet. 2018;50:524-537. doi: 10.1038/s41588-018-0058-3

19. Nikpay M, Goel A, Won HH, Hall LM, Willenborg C, Kanoni S, Saleheen D, Kyriakou T, Nelson CP, Hopewell JC, et al. A comprehensive 1000 Genomes-based genome-wide association meta-analysis of coronary artery disease. Nat Genet. 2015;47:1121-1130. doi: 10.1038/ng.3396

20. Shah S, Henry A, Roselli C, Lin H, Sveinbjörnsson G, Fatemifar G, Hedman ÅK, Wilk JB, Morley MP, Chaffin MD, et al. Genome-wide association and Mendelian randomisation analysis provide insights into the pathogenesis of heart failure. Nat Commun. 2020;11:163. doi: 10.1038/s41467-019-13690-5

21. Roselli C, Chaffin MD, Weng L-C, Aeschbacher S, Ahlberg G, Albert $\mathrm{CM}$, Almgren $\mathrm{P}$, Alonso A, Anderson CD, Aragam KG, et al. Multiethnic genome-wide association study for atrial fibrillation. Nat Genet. 2018;50:1225-1233. doi: 10.1038/s41588-018-0133-9

22. Lindsberg PJ, Grau AJ. Inflammation and infections as risk factors for ischemic stroke. Stroke. 2003;34:2518-2532. doi: 10.1161/01. STR.0000089015.51603.CC

23. Toyoda K, Ninomiya T. Stroke and cerebrovascular diseases in patients with chronic kidney disease. Lancet Neurol. 2014;13:823-833. doi: 10.1016/S1474-4422(14)70026-2

24. Kernan WN, Inzucchi SE, Sawan C, Macko RF, Furie KL. Obesity: a stubbornly obvious target for stroke prevention. Stroke. 2013;44:278286. doi: 10.1161/STROKEAHA.111.639922

25. Wolf PA, D'Agostino RB, Kannel WB, Bonita R, Belanger AJ. Cigarette smoking as a risk factor for stroke. The Framingham Study. JAMA. 1988;259:1025-1029. doi: 10.1001/jama.1988.03720070025028

26. Pulit SL, Stoneman C, Morris AP, Wood AR, Glastonbury CA, Tyrrell J, Yengo L, Ferreira T, Marouli E, Ji Y, et al. Meta-analysis of genome-wide association studies for body fat distribution in 694649 individuals of European ancestry. Hum Mol Genet. 2019;28:166-174. doi: 10.1093/ $\mathrm{hmg} / \mathrm{ddy} 327$

27. Wootton RE, Richmond RC, Stuijfzand BG, Lawn RB, Sallis HM, Taylor GMJ, Hemani G, Jones HJ, Zammit S, Davey Smith G, et al. Evidence for causal effects of lifetime smoking on risk for depression and schizophrenia: a Mendelian randomisation study. Psychol Med. 2020;50:2435-2443. doi: 10.1017/S0033291719002678

28. Neale lab. Rapid GWAS of thousands of phenotypes in the UK Biobank 2020. http://www.nealelab.is/uk-biobank/

29. Bulik-Sullivan B, Finucane HK, Anttila V, Gusev A, Day FR, Loh PR, Duncan L, Perry JRB, Patterson N, Robinson EB, et al. An atlas of genetic correlations across human diseases and traits. Nat Genet. 2015;47:1236-1241. doi: 10.1038/ng.3406

30. Benjamini $Y$, Yekutieli $D$. The control of the false discovery rate in multiple testing under dependency. Ann Stat. 2001;29:1165-1188. doi: 10.1214/aos/1013699998

31. Pierce BL, Burgess S. Efficient design for mendelian randomization studies: subsample and 2-sample instrumental variable estimators. Am J Epidemiol. 2013;178:1177-1184. doi: 10.1093/aje/kwt084

32. Del Greco MF, Minelli C, Sheehan NA, Thompson JR. Detecting pleiotropy in Mendelian randomisation studies with summary data and a continuous outcome. Stat Med. 2015;34:2926-2940. doi: 10.1002/ sim.6522 
33. Bowden J, Davey Smith G, Haycock PC, Burgess S. Consistent estimation in Mendelian randomization with some invalid instruments using a weighted median estimator. Genet Epidemiol. 2016;40:304-314. doi: 10.1002/gepi.21965

34. Bowden J, Davey Smith G, Burgess S. Mendelian randomization with invalid instruments: effect estimation and bias detection through Egger regression. Int J Epidemiol. 2015;44:512-525. doi: 10.1093/ije/dyv080

35. Bowden J, Smith GD, Haycock PC, Burgess S. Consistent estimation in mendelian randomization with some invalid instruments using a weighted median estimator. Genet Epidemiol. 2016;40:304-314. doi: 10.1002/gepi.21965

36. Burgess S, Thompson SG. Multivariable Mendelian randomization: the use of pleiotropic genetic variants to estimate causal effects. Am J Epidemiol. 2015;181:251-260. doi: 10.1093/aje/kwu283

37. Burgess S, Thompson DJ, Rees JMB, Day FR, Perry JR, Ong KK Dissecting causal pathways using Mendelian randomization with summarized genetic data: application to age at menarche and risk of breast cancer. Genetics. 2017;207:481-487. doi: 10.1534/genetics.117.300191

38. Burgess S. Sample size and power calculations in Mendelian randomization with a single instrumental variable and a binary outcome. Int $J$ Epidemiol. 2014;43:922-929. doi: 10.1093/ije/dyu005

39. Burgess S, Thompson SG, Collaboration CRPCHDG. Avoiding bias from weak instruments in Mendelian randomization studies. Int $J$ Epidemiol. 2011;40:755-764. doi: 10.1093/ije/dyr036

40. Yavorska OO, Burgess S. MendelianRandomization: an R package for performing Mendelian randomization analyses using summarized data. Int J Epidemiol. 2017:46:1734-1739. doi: 10.1093/ije/dyx034

41. Adams HP, Bendixen BH, Kappelle LJ, Biller J, Love BB, Gordon DL, Marsh EE. Classification of subtype of acute ischemic stroke. Definitions for use in a multicenter clinical trial. TOAST. Trial of Org 10172 in acute stroke treatment. Stroke. 1993;24:35-41. doi: 10.1161/01.STR.24.1.35
42. Aguiar de Sousa D, Sandset EC, Elkind MSV. The curious case of the missing strokes during the COVID-19 pandemic. Stroke. 2020:51:19211923. doi: 10.1161/STROKEAHA.120.030792

43. Varga Z, Flammer AJ, Steiger $P$, Haberecker $M$, Andermatt $R$, Zinkernagel AS, Mehra MR, Schuepbach RA, Ruschitzka F, Moch $\mathrm{H}$. Endothelial cell infection and endotheliitis in COVID-19. Lancet. 2020;395:1417-1418. doi: 10.1016/S0140-6736(20)30937-5

44. Lee SG, Fralick M, Sholzberg M. Coagulopathy associated with COVID-19. Can Med Ass J. 2020;192:E583. doi: 10.1503/cmaj.200685

45. Fauvel C, Weizman O, Trimaille A, Mika D, Pommier T, Pace N, Douair A Barbin E, Fraix A, Bouchot O, et al. Pulmonary embolism in COVID-19 patients: a French multicentre cohort study. Eur Heart J. 2020;41:30583068. doi: 10.1093/eurheartj/ehaa500

46. Robinson RG, Bolduc PL, Price TR. Two-year longitudinal study of poststroke mood disorders: diagnosis and outcome at one and two years. Stroke. 1987;18:837-843. doi: 10.1161/01.STR.18.5.837

47. Georgakis MK, Malik R, Gill D, Franceschini N, Sudlow CLM, Dichgans M. Interleukin-6 signaling effects on ischemic stroke and other cardiovascular outcomes: a Mendelian randomization study. Circ Genom Precis Med. 2020;13:e002872. doi: 10.1161/CIRCGEN.119.002872

48. Larsson S, Burgess S, Gill D. Genetically proxied inhibition of interleukin-6 signaling: opposing associations with susceptibility to COVID-19 and pneumonia. Eur Respir J. 2021;57:2003545

49. Salama C, Han J, Yau L, Reiss WG, Kramer B, Neidhart JD, Criner GJ, Kaplan-Lewis E, Baden R, Pandit L, et al. Tocilizumab in patients hospitalized with COVID-19 pneumonia. New Engl J Med. 2021;384:20-30. doi: 10.1056/NEJMoa2030340

50. Coull AJ, Lovett JK, Rothwell PM. Population based study of early risk of stroke after transient ischaemic attack or minor stroke: implications for public education and organisation of services. BMJ. 2004;328:326. doi: 10.1136/bmj.37991.635266.44 


\section{Supplemental Material}


Table S1: Overview of the publicly available summary-level data of genetic associations used for the analysis.

\begin{tabular}{|c|c|c|c|c|c|c|c|}
\hline Phenotype & Description & $\begin{array}{c}\text { Sample } \\
\text { Size }\end{array}$ & Cases & Controls & Population & Pubmed & Author \\
\hline \multirow{4}{*}{ Covid-19 } & Main: Critical Covid vs. population & & 5,101 & $1,383,241$ & \multirow{4}{*}{ EUR } & & \multirow{4}{*}{$\begin{array}{l}\text { The COVID-19 } \\
\text { Host Genetics } \\
\text { Initiative (2021) }\end{array}$} \\
\hline & $\begin{array}{l}\text { Sensitivity Analysis 1: Hospitalized Covid vs. not hospitalized } \\
\text { Covid }\end{array}$ & & 4,829 & 11,816 & & & \\
\hline & Sensitivity Analysis 2: Hospitalized Covid vs. population & & 9,986 & $1,877,672$ & & & \\
\hline & Sensitivity Analysis 3: Covid vs population & & 38,984 & $1,644,784$ & & & \\
\hline \multirow{4}{*}{ Stroke } & Any ischemic stroke & & 34,217 & 406,111 & \multirow{4}{*}{ EUR } & \multirow{4}{*}{29531354} & \multirow{4}{*}{ Malik et al. (2018) } \\
\hline & Large artery stroke & & 4,373 & 406,111 & & & \\
\hline & Cardioembolic stroke & & 7,193 & 406,111 & & & \\
\hline & Small vessel stroke & & 5,386 & 406,111 & & & \\
\hline \multirow{3}{*}{$\begin{array}{l}\text { Cardiovascular disease } \\
\text { outcomes }\end{array}$} & Coronary artery disease & & 60,801 & 123,504 & EUR, SEA & 26343387 & Nikpay et al. (2015) \\
\hline & Heart failure & & 47,309 & 930,014 & EUR & 31919418 & Shah et al. (2020) \\
\hline & Atrial fibrillation & & 65,446 & 522,744 & TRANS & 29892015 & Roselli et al. (2018) \\
\hline Obesity & Body mass index & 694,649 & & & EUR & 30239722 & Pullit et al. (2019) \\
\hline Smoking & Lifetime smoking index & 462,690 & & & EUR & 30239722 & $\begin{array}{l}\text { Wootton et al. } \\
\qquad(2020)\end{array}$ \\
\hline Inflammation & C-reactive protein & 361,194 & & & EUR & & Neale lab \\
\hline
\end{tabular}


Table S2. Cross-trait linkage disequilibrium score regression (LDSC) analysis results of critical Covid-19 with ischemic stroke, cardiovascular disease (CVD) outcomes, and risk factors related to both Covid-19 and CVD. $\mathrm{r}_{\mathrm{g}}$ represents the genetic correlation between critical Covid-19 and each phenotype. $p$-values are corrected for multiple testing with the Benjamini and Hochberg false discovery rate (FDR).

\begin{tabular}{|c|c|c|}
\hline & $\mathbf{r}_{\mathbf{g}}$ & FDR- $\boldsymbol{p}$ value \\
\hline Ischemic stroke & 0.2922 & $4.65 \mathrm{E}-03$ \\
\hline Coronary artery disease & 0.1914 & $7.60 \mathrm{E}-02$ \\
\hline Heart failure & 0.1491 & $1.12 \mathrm{E}-01$ \\
\hline Atrial fibrillation & 0.0198 & $7.17 \mathrm{E}-01$ \\
\hline Body mass index & 0.2088 & $6.26 \mathrm{E}-06$ \\
\hline Smoking & 0.1029 & $5.91 \mathrm{E}-02$ \\
\hline C-reactive protein & 0.2006 & $1.35 \mathrm{E}-04$ \\
\hline
\end{tabular}


Table S3: Overview of the genetic variants used as instrumental variables for liability to critical Covid-19 based on the Covid-19 host genetics initiative. We selected 31 uncorrelated (clumped at correlation threshold $r^{2}<0.01$ ) genetic variants as instrumental variables for laibility to critical Covid-19 that were associated at a $p$-value level of $5 \times 10^{-6}$ or smaller. The table additionally includes summary-level data (beta coefficients of genetic association, their standard error and corresponding $p$-value) for liability to critical Covid-19 as exposure and any ischemic stroke (AIS) and its subtypes cardioembolic stroke (CES), large artery stroke (LAS), and small vessel stroke (SVS) as outcomes. Alt: alternative allele; Chr: chromosome; Pos: position; Ref: reference allele; SE: standard error.

\begin{tabular}{|c|c|c|c|c|c|c|c|c|c|c|c|c|c|c|c|c|c|c|c|}
\hline \multirow[b]{2}{*}{ Variant } & \multirow[b]{2}{*}{ Chr } & \multirow[b]{2}{*}{ Pos } & \multirow[b]{2}{*}{ Ref } & \multirow[b]{2}{*}{ Alt } & \multicolumn{3}{|c|}{ Critical Covid-19 } & \multicolumn{3}{|c|}{ AIS } & \multicolumn{3}{|c|}{ CES } & \multicolumn{3}{|c|}{ LAS } & \multicolumn{3}{|c|}{ SVS } \\
\hline & & & & & Beta & SE & $\mathbf{P}$ & Beta & SE & $\mathbf{P}$ & Beta & SE & $\mathbf{P}$ & Beta & SE & $\mathbf{P}$ & Beta & SE & $\mathbf{P}$ \\
\hline rs10087754 & 8 & 121819908 & $\mathrm{~T}$ & A & 1 & 2 & 7 & 2 & 2 & 1 & 4 & 2 & $9.9 \mathrm{E}-01$ & 2 & 2 & 2 & 3 & 2 & $8 \mathrm{E}-01$ \\
\hline rs11085727 & 19 & 10355447 & $\mathrm{C}$ & $\mathrm{T}$ & 1.7E-01 & $9 \mathrm{E}-02$ & $7 \mathrm{E}-09$ & $-2.2 \mathrm{E}-02$ & $1.1 \mathrm{E}-02$ & $5.2 \mathrm{E}-02$ & $5 \mathrm{E}-02$ & $2.2 \mathrm{E}-02$ & $1 \mathrm{E}-02$ & $-5.0 \mathrm{E}-04$ & $2.8 \mathrm{E}-02$ & $9.8 \mathrm{E}-01$ & $3.5 \mathrm{E}-02$ & $2.5 \mathrm{E}-02$ & $1.7 \mathrm{E}-01$ \\
\hline rs111508230 & 1 & 155181061 & $\mathrm{C}$ & $\mathrm{T}$ & $-2.1 \mathrm{E}-01$ & $4.4 \mathrm{E}-02$ & $2.6 \mathrm{E}-06$ & $-8.1 \mathrm{E}-03$ & $1.6 \mathrm{E}-02$ & $6.1 \mathrm{E}-01$ & $-7.1 \mathrm{E}-02$ & $3.1 \mathrm{E}-02$ & $2.4 \mathrm{E}-02$ & $9.3 \mathrm{E}-02$ & $3.9 \mathrm{E}-02$ & $1.7 \mathrm{E}-02$ & $2.9 \mathrm{E}-02$ & $4.1 \mathrm{E}-02$ & $4.8 \mathrm{E}-01$ \\
\hline rs114969787 & 5 & 65770656 & $\mathrm{C}$ & $\mathrm{T}$ & $3.1 \mathrm{E}-01$ & $6.6 \mathrm{E}-02$ & $3.6 \mathrm{E}-06$ & $4.1 \mathrm{E}-02$ & $3.1 \mathrm{E}-02$ & $1.9 \mathrm{E}-01$ & $-4.7 \mathrm{E}-02$ & $6.4 \mathrm{E}-02$ & $4.7 \mathrm{E}-01$ & $1.2 \mathrm{E}-01$ & $7.7 \mathrm{E}-02$ & $1.4 \mathrm{E}-01$ & $4.4 \mathrm{E}-02$ & $7.2 \mathrm{E}-02$ & $5.5 \mathrm{E}-01$ \\
\hline rs11658357 & 17 & 36097317 & A & $\mathrm{T}$ & $-2.0 \mathrm{E}-01$ & $4.4 \mathrm{E}-02$ & $4.9 \mathrm{E}-06$ & $9.7 \mathrm{E}-03$ & $1.3 \mathrm{E}-02$ & $4.4 \mathrm{E}-01$ & $-1.8 \mathrm{E}-02$ & $2.4 \mathrm{E}-02$ & $4.5 \mathrm{E}-01$ & $-1.5 \mathrm{E}-02$ & $3.1 \mathrm{E}-02$ & $6.1 \mathrm{E}-01$ & $4.4 \mathrm{E}-02$ & $2.9 \mathrm{E}-02$ & $1.3 \mathrm{E}-01$ \\
\hline rs117232645 & 13 & 74553195 & G & $\mathrm{A}$ & $-3.3 \mathrm{E}-01$ & $7.0 \mathrm{E}-02$ & $2.5 \mathrm{E}-06$ & $-3.1 \mathrm{E}-02$ & $3.0 \mathrm{E}-02$ & $3.0 \mathrm{E}-01$ & $1.0 \mathrm{E}-02$ & $5.9 \mathrm{E}-02$ & $8.6 \mathrm{E}-01$ & 4.4E-02 & $7.3 \mathrm{E}-02$ & $5.4 \mathrm{E}-01$ & $3.8 \mathrm{E}-03$ & $6.8 \mathrm{E}-02$ & $9.6 \mathrm{E}-01$ \\
\hline rs13050728 & 21 & 33242905 & $\mathrm{~T}$ & $\mathrm{C}$ & $-2.0 \mathrm{E}-01$ & $2.9 \mathrm{E}-02$ & $2.4 \mathrm{E}-12$ & $-4.4 \mathrm{E}-03$ & $1.1 \mathrm{E}-02$ & $6.8 \mathrm{E}-01$ & $-2.9 \mathrm{E}-02$ & $2.0 \mathrm{E}-02$ & $1.5 \mathrm{E}-01$ & $-2.7 \mathrm{E}-02$ & $2.6 \mathrm{E}-02$ & $3.1 \mathrm{E}-01$ & $2.7 \mathrm{E}-02$ & $2.5 \mathrm{E}-02$ & $2.8 \mathrm{E}-01$ \\
\hline rs 13080258 & 3 & (2) & A & $\mathrm{C}$ & - & $3.0 \mathrm{E}-02$ & $3.6 \mathrm{E}-06$ & 2.00 & $1.2 \mathrm{E}-02$ & $8.1 \mathrm{E}-01$ & $6.8 \mathrm{E}-03$ & $2.3 \mathrm{E}-02$ & $7.6 \mathrm{E}-01$ & $-1.6 \mathrm{E}-02$ & $2.9 \mathrm{E}-02$ & $5.9 \mathrm{E}-01$ & $-1.8 \mathrm{E}-02$ & $2.7 \mathrm{E}-02$ & $5.1 \mathrm{E}-01$ \\
\hline rs 13274496 & 8 & 22583385 & G & A & $-2.0 \mathrm{E}-01$ & $4.2 \mathrm{E}-02$ & $1.8 \mathrm{E}-06$ & $7.0 \mathrm{E}-04$ & $1.3 \mathrm{E}-02$ & $9.6 \mathrm{E}-01$ & $1.7 \mathrm{E}-02$ & $2.4 \mathrm{E}-02$ & $4.8 \mathrm{E}-01$ & $-1.9 \mathrm{E}-02$ & $3.2 \mathrm{E}-02$ & $5.5 \mathrm{E}-01$ & $-3.2 \mathrm{E}-02$ & $2.9 \mathrm{E}-02$ & $2.6 \mathrm{E}-01$ \\
\hline rs143334143 & 6 & 31153649 & G & A & $2.9 \mathrm{E}-01$ & 4.3E-02 & $6.0 \mathrm{E}-12$ & $9.0 \mathrm{E}-03$ & $1.9 \mathrm{E}-02$ & $6.4 \mathrm{E}-01$ & $3.6 \mathrm{E}-02$ & $3.6 \mathrm{E}-02$ & $3.1 \mathrm{E}-01$ & $-1.0 \mathrm{E}-02$ & $4.8 \mathrm{E}-02$ & $8.3 \mathrm{E}-01$ & $3.6 \mathrm{E}-02$ & $4.6 \mathrm{E}-02$ & 4.3E-01 \\
\hline rs 1974792 & 19 & 50353078 & A & G & $-1.4 \mathrm{E}-01$ & $2.7 \mathrm{E}-02$ & $5.1 \mathrm{E}-07$ & $-2.0 \mathrm{E}-02$ & $1.0 \mathrm{E}-02$ & 4.7E-02 & $-9.6 \mathrm{E}-03$ & $2.0 \mathrm{E}-02$ & $6.3 \mathrm{E}-01$ & $-6.3 \mathrm{E}-02$ & $2.5 \mathrm{E}-02$ & $1.3 \mathrm{E}-02$ & $3.2 \mathrm{E}-02$ & $2.4 \mathrm{E}-02$ & $1.8 \mathrm{E}-01$ \\
\hline rs2109069 & 19 & 4719431 & G & A & $2.6 \mathrm{E}-01$ & $2.8 \mathrm{E}-02$ & $6.1 \mathrm{E}-20$ & $-7.1 \mathrm{E}-03$ & $1.1 \mathrm{E}-02$ & $5.2 \mathrm{E}-01$ & $2.0 \mathrm{E}-03$ & $2.2 \mathrm{E}-02$ & $9.3 \mathrm{E}-01$ & $-6.2 \mathrm{E}-03$ & $2.7 \mathrm{E}-02$ & $8.2 \mathrm{E}-01$ & $-1.1 \mathrm{E}-02$ & $2.6 \mathrm{E}-02$ & $6.8 \mathrm{E}-01$ \\
\hline $\mathrm{rs} 223$ & 7 & 7 & $\mathrm{C}$ & $\mathrm{T}$ & 政 & $4.0 \mathrm{E}-02$ & 9 & 2 & 2 & $1.9 \mathrm{E}-01$ & $-2.7 \mathrm{E}-02$ & $3.9 \mathrm{E}-02$ & T & 02 & -02 & 1 & $-2.3 \mathrm{E}-02$ & 1.7E- 02 & $3 \mathrm{E}-01$ \\
\hline rs2597569 & 11 & 1 & $\mathrm{~T}$ & $\mathrm{C}$ & $-1.8 \mathrm{E}-01$ & $\mathrm{E}-02$ & $9.3 \mathrm{E}-08$ & $-7.0 \mathrm{E}-03$ & $1.0 \mathrm{E}-02$ & 4.9E-01 & 02 & $9 \mathrm{E}-02$ & $4.5 \mathrm{E}-01$ & $3 \mathrm{E}-02$ & $.5 \mathrm{E}-02$ & $2.0 \mathrm{E}-01$ & $-3.5 \mathrm{E}-02$ & $2.4 \mathrm{E}-02$ & $1.4 \mathrm{E}-01$ \\
\hline rs2733839 & 12 & 10393411 & $\mathrm{~T}$ & $\mathrm{C}$ & $2.7 \mathrm{E}-01$ & $5.8 \mathrm{E}-02$ & $3.5 \mathrm{E}-06$ & $-3.9 \mathrm{E}-03$ & $2.7 \mathrm{E}-02$ & $8.9 \mathrm{E}-01$ & $4.3 \mathrm{E}-02$ & $5.3 \mathrm{E}-02$ & $4.2 \mathrm{E}-01$ & $-4.1 \mathrm{E}-02$ & $7.2 \mathrm{E}-02$ & $5.7 \mathrm{E}-01$ & $3.0 \mathrm{E}-02$ & $6.4 \mathrm{E}-02$ & $6.4 \mathrm{E}-01$ \\
\hline rs340850 & 1 & 213941523 & $\mathrm{~T}$ & G & $-2.8 \mathrm{E}-01$ & $6.0 \mathrm{E}-02$ & $4.3 \mathrm{E}-06$ & $2.0 \mathrm{E}-02$ & $2.4 \mathrm{E}-02$ & 4.0E-01 & $5.6 \mathrm{E}-02$ & $4.8 \mathrm{E}-02$ & $2.5 \mathrm{E}-01$ & $-9.7 \mathrm{E}-02$ & $5.7 \mathrm{E}-02$ & $9.0 \mathrm{E}-02$ & $-5.3 \mathrm{E}-02$ & $5.5 \mathrm{E}-02$ & $3.3 \mathrm{E}-01$ \\
\hline rs35081325 & 3 & 45848420 & A & $\mathrm{T}$ & $6.3 \mathrm{E}-01$ & $45 \mathrm{~F}_{-}-2 ?$ & $5.8 \mathrm{E}-45$ & $30 F_{-} 0 ?$ & $2.0 \mathrm{E}-02$ & $13 \mathrm{~F}_{0} 01$ & 4.3E-02 & $3.8 \mathrm{E}-02$ & $2.6 \mathrm{E}-01$ & $5.4 \mathrm{E}-02$ & $5.1 \mathrm{E}-02$ & $2.8 \mathrm{E}-01$ & $2.7 \mathrm{E}-02$ & 4.9E-02 & $5.9 \mathrm{E}-01$ \\
\hline rs36932 & 7 & 123877938 & G & A & $6 \mathrm{E}-01$ & $3.4 \mathrm{E}-0$ & $4.0 \mathrm{E}-06$ & $2 \mathrm{E}-03$ & $1.4 \mathrm{E}-02$ & $6.5 \mathrm{E}$ & $-2.1 \mathrm{E}-02$ & $2.6 \mathrm{E}-\mathrm{C}$ & $4.3 \mathrm{E}-$ & $-3.2 \mathrm{E}$ & $3.3 \mathrm{E}-02$ & (J.J1 & $.8 \mathrm{E}-02$ & $3.1 \mathrm{E}-02$ & $1.2 \mathrm{E}-01$ \\
\hline rs 4076440 & 1 & 9630418 & A & G & $2.1 \mathrm{E}-01$ & $4.3 \mathrm{E}-02$ & $9.4 \mathrm{E}-07$ & $-1.5 \mathrm{E}-02$ & $2.1 \mathrm{E}-02$ & 4.7E-01 & $4.2 \mathrm{E}-03$ & $4.1 \mathrm{E}-02$ & $9.2 \mathrm{E}-01$ & $-5.8 \mathrm{E}-02$ & $5.3 \mathrm{E}-02$ & $2.7 \mathrm{E}-01$ & $5.1 \mathrm{E}-03$ & $4.8 \mathrm{E}-02$ & $9.2 \mathrm{E}-01$ \\
\hline rs5767981 & 22 & 47769327 & A & G & $-1.6 \mathrm{E}-01$ & $3.4 \mathrm{E}-02$ & $5.0 \mathrm{E}-06$ & $-2.0 \mathrm{E}-02$ & $1.1 \mathrm{E}-02$ & $5.7 \mathrm{E}-02$ & $-7.9 \mathrm{E}-03$ & $2.1 \mathrm{E}-02$ & $7.0 \mathrm{E}-01$ & $-3.0 \mathrm{E}-03$ & $2.7 \mathrm{E}-02$ & $9.1 \mathrm{E}-01$ & $-2.6 \mathrm{E}-02$ & $2.5 \mathrm{E}-02$ & $2.9 \mathrm{E}-01$ \\
\hline rs 6 & 7 & 1 & A & $\mathrm{C}$ & 1 & $37 \mathrm{~F}_{-}-02$ & 1. & 3 & 22 & 8 & $5.2 \mathrm{E}$ & $2.6 \mathrm{E}$ & 4.4E-02 & 02 & 02 & 9.11 & -1.7 & 2 & $5.8 \mathrm{E}-01$ \\
\hline rs633862 & 9 & 133279871 & $\mathrm{~T}$ & $\mathrm{C}$ & $-1.7 \mathrm{E}-01$ & $3.4 \mathrm{E}-02$ & $1.1 \mathrm{E}-06$ & $-2.6 \mathrm{E}-02$ & $1.0 \mathrm{E}-02$ & $1.2 \mathrm{E}-02$ & $-5.5 \mathrm{E}-02$ & $1.9 \mathrm{E}-02$ & $3.8 \mathrm{E}-03$ & $-5.1 \mathrm{E}-02$ & $2.4 \mathrm{E}-02$ & $3.7 \mathrm{E}-02$ & $-1.0 \mathrm{E}-04$ & $2.3 \mathrm{E}-02$ & $1.0 \mathrm{E}+00$ \\
\hline rs6478109 & 9 & 114806486 & A & G & $1.5 \mathrm{E}-01$ & $2.8 \mathrm{E}-02$ & $2.4 \mathrm{E}-07$ & $1.2 \mathrm{E}-02$ & $1.1 \mathrm{E}-02$ & $2.5 \mathrm{E}-01$ & $2.2 \mathrm{E}-02$ & $2.1 \mathrm{E}-02$ & $2.8 \mathrm{E}-01$ & $6.0 \mathrm{E}-02$ & $2.7 \mathrm{E}-02$ & $2.7 \mathrm{E}-02$ & 4.4E-02 & $2.5 \mathrm{E}-02$ & 7.4E-02 \\
\hline rs6712600 & 2 & 125728622 & G & A & $-1.7 \mathrm{E}-01$ & $3.4 \mathrm{E}-02$ & $3.3 \mathrm{E}-07$ & $6.9 \mathrm{E}-03$ & $1.3 \mathrm{E}-02$ & $5.8 \mathrm{E}-01$ & $5.0 \mathrm{E}-02$ & $2.4 \mathrm{E}-02$ & $3.7 \mathrm{E}-02$ & $-9.4 \mathrm{E}-03$ & $3.1 \mathrm{E}-02$ & 7.6E-01 & $-3.1 \mathrm{E}-02$ & $2.9 \mathrm{E}-02$ & $2.8 \mathrm{E}-01$ \\
\hline
\end{tabular}




\begin{tabular}{|c|c|c|c|c|c|c|c|c|c|c|c|c|c|c|c|c|c|c|c|}
\hline rs7135260 & 12 & 112943944 & $\mathrm{~T}$ & $\mathrm{C}$ & $1.9 \mathrm{E}-01$ & $2.8 \mathrm{E}-02$ & $6.1 \mathrm{E}-12$ & $2.6 \mathrm{E}-02$ & $1.1 \mathrm{E}-02$ & $1.5 \mathrm{E}-02$ & $0.0 \mathrm{E}+00$ & $2.1 \mathrm{E}-02$ & $1.0 \mathrm{E}+00$ & $4.0 \mathrm{E}-02$ & $2.7 \mathrm{E}-02$ & $1.4 \mathrm{E}-01$ & $4.1 \mathrm{E}-02$ & $2.5 \mathrm{E}-02$ & $1.0 \mathrm{E}-01$ \\
\hline rs 77406469 & 7 & 150758864 & $\mathrm{C}$ & $\mathrm{T}$ & 3.4E-01 & $9 \mathrm{E}-02$ & $6.5 \mathrm{E}-07$ & $1.8 \mathrm{E}-02$ & $2.7 \mathrm{E}-02$ & $5.1 \mathrm{E}-01$ & $4.3 \mathrm{E}-02$ & $6.0 \mathrm{E}-02$ & 4.7E-01 & $5.4 \mathrm{E}-02$ & 7.6E-02 & $4.8 \mathrm{E}-01$ & $6.6 \mathrm{E}-02$ & $6.8 \mathrm{E}-02$ & $3.3 \mathrm{E}-01$ \\
\hline rs 77534576 & 17 & 49863303 & $\mathrm{C}$ & $\mathrm{T}$ & $6 \mathrm{E}-01$ & $5 \mathrm{E}-02$ & $8.5 \mathrm{E}-10$ & $2.8 \mathrm{E}-02$ & $3.1 \mathrm{E}-02$ & $3.7 \mathrm{E}-01$ & $4 \mathrm{E}-02$ & $6.6 \mathrm{E}-02$ & 4.1E-01 & 7.3E-02 & $8.2 \mathrm{E}-02$ & $3.7 \mathrm{E}-01$ & $1.3 \mathrm{E}-01$ & $7.6 \mathrm{E}-02$ & 7.6E-02 \\
\hline rs79833209 & 5 & 163300447 & $\mathrm{C}$ & $\mathrm{T}$ & 4.4E-01 & $9.2 \mathrm{E}-02$ & $2.2 \mathrm{E}-06$ & $1.0 \mathrm{E}-01$ & $3.6 \mathrm{E}-02$ & $3.9 \mathrm{E}-03$ & $8.1 \mathrm{E}-02$ & 7.9E-02 & 3.0E-01 & $-8.4 \mathrm{E}-03$ & $9.9 \mathrm{E}-02$ & $9.3 \mathrm{E}-01$ & $-2.0 \mathrm{E}-02$ & $9.0 \mathrm{E}-02$ & $8.2 \mathrm{E}-01$ \\
\hline rs9287218 & 1 & 027112700 & A & c & 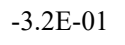 & 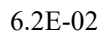 & $39 E_{0} 0$ & 0 & $2.4 \mathrm{E}$ & $9.1 \mathrm{E}$ & $2.3 \mathrm{E}-02$ & 4 & 6,3501 & 1 & 02 & 1 & 02 & 02 & 4.0 \\
\hline rs9577175 & 13 & 112889041 & $\mathrm{C}$ & $\mathrm{T}$ & 2.0E-01 & E-02 & $7.9 \mathrm{E}-07$ & $-4.0 \mathrm{E}-03$ & $1.2 \mathrm{E}-02$ & 7.3E-01 & $3.8 \mathrm{E}-03$ & $2.3 \mathrm{E}-02$ & $8.7 \mathrm{E}-01$ & $-2.5 \mathrm{E}-02$ & $3.0 \mathrm{E}-02$ & 4.0E- 01 & $1.2 \mathrm{E}-02$ & $2.8 \mathrm{E}-02$ & $6.7 \mathrm{E}-01$ \\
\hline rs9871880 & 3 & 197399535 & $\mathrm{C}$ & $\mathrm{T}$ & $-2.5 \mathrm{E}-01$ & $5.0 \mathrm{E}-02$ & $4.1 \mathrm{E}-07$ & $-2.7 \mathrm{E}-03$ & $1.8 \mathrm{E}-02$ & $8.8 \mathrm{E}-01$ & $-1.0 \mathrm{E}-01$ & $3.6 \mathrm{E}-02$ & $4.1 \mathrm{E}-03$ & $5.4 \mathrm{E}-02$ & $4.4 \mathrm{E}-02$ & $2.2 \mathrm{E}-01$ & $1.0 \mathrm{E}-02$ & $4.2 \mathrm{E}-02$ & $8.1 \mathrm{E}-01$ \\
\hline
\end{tabular}


Table S4: Sensitivity analysis for the Mendelian randomization analysis of liability to critical Covid-19 on ischemic stroke outcomes including the inverse-variance weighted (IVW) Mendelian randomization and pleiotropy-robust Mendelian randomization approaches (simple, weighted median and MR-Egger). Mendelian randomization estimates represent the odds ratio for ischemic stroke outcomes per unit increase in the log-odds ratio of liability to critical Covid-19. In addition to the Mendelian randomization estimates, we included their 95\% confidence interval (CI) and corresponding $p$-value. The intercept of the MR-Egger method was used to test for directional pleiotropy. Instrument selection was based on genetic variants that were associated with liability to critical Covid-19 with a $p$-value equal to or smaller than $5 \times 10^{-6}$. Main outcome was any ischemic stroke, and we further included the subtypes cardioembolic stroke, large artery stroke, and small vessel stroke.

\begin{tabular}{|c|c|c|c|c|c|}
\hline Outcome & Method & Estimate & $\begin{array}{c}\text { 95\% CI } \\
\text { Lower }\end{array}$ & $\begin{array}{c}\text { 95\% CI } \\
\text { Upper }\end{array}$ & $p$-value \\
\hline \multirow{5}{*}{$\begin{array}{c}\text { Any } \\
\text { ischemic } \\
\text { stroke }\end{array}$} & IVW & 1.031 & 1.004 & 1.058 & 0.027 \\
\hline & Simple median & 1.022 & 0.986 & 1.059 & 0.227 \\
\hline & Weighted median & 1.031 & 0.995 & 1.068 & 0.088 \\
\hline & MR-Egger & 1.022 & 0.947 & 1.103 & 0.573 \\
\hline & MR-Egger intercept & 0.002 & -0.014 & 0.018 & 0.820 \\
\hline \multirow{5}{*}{$\begin{array}{c}\text { Cardio- } \\
\text { embolic } \\
\text { stroke }\end{array}$} & IVW & 1.060 & 1.005 & 1.119 & 0.034 \\
\hline & Simple median & 1.072 & 1.001 & 1.147 & 0.047 \\
\hline & Weighted median & 1.072 & 1.001 & 1.147 & 0.046 \\
\hline & MR-Egger & 1.092 & 0.935 & 1.276 & 0.266 \\
\hline & MR-Egger intercept & -0.007 & -0.040 & 0.026 & 0.689 \\
\hline \multirow{5}{*}{$\begin{array}{l}\text { Large } \\
\text { artery } \\
\text { stroke }\end{array}$} & IVW & 1.067 & 0.997 & 1.141 & 0.059 \\
\hline & Simple median & 1.079 & 0.988 & 1.180 & 0.091 \\
\hline & Weighted median & 1.087 & 0.994 & 1.188 & 0.066 \\
\hline & MR-Egger & 0.919 & 0.762 & 1.108 & 0.374 \\
\hline & MR-Egger intercept & 0.034 & -0.006 & 0.073 & 0.095 \\
\hline \multirow{5}{*}{$\begin{array}{c}\text { Small vessel } \\
\text { stroke }\end{array}$} & IVW & 1.054 & 0.999 & 1.112 & 0.055 \\
\hline & Simple median & 1.075 & 0.990 & 1.167 & 0.087 \\
\hline & Weighted median & 1.051 & 0.968 & 1.140 & 0.237 \\
\hline & MR-Egger & 1.012 & 0.867 & 1.182 & 0.879 \\
\hline & MR-Egger intercept & 0.009 & -0.024 & 0.042 & 0.585 \\
\hline
\end{tabular}


Table S5: Likelihood ratio test to compare the model fit of the multivariable Mendelian randomization model considering risk for critical Covid-19 as exposure for ischemic stroke outcomes accounting for potential pleiotropic pathways (including life-time smoking index, body mass index, and c-reactive protein) with the univariable Mendelian randomization model. Model fit is evaluated using residual sum of squares for the univariable Mendelian randomization model (RSS 1) with the residual sum of squares for the multivariable Mendelian randomization model (RSS 2). There was one degree of freedom difference between the multivariable and the univariable Mendelian randomization model because there is one additional parameter to estimate in the multivariable Mendelian randomization model. The $F$-statistic quantifies the reduction in residual sum of squares by adding the pleiotropic risk factor to the Mendelian randomization model. The respective $p$-value tests if the multivariable Mendelian randomization model including the pleiotropic pathways provides a significantly better model fit of the genetic association estimates with the stroke outcome than the univariable Mendelian randomization model. Instrument selection was based on genetic variants that were associated with liability to critical Covid-19 with a $p$-value equal to or smaller than $5 \times 10^{-6}$. Main outcome was any ischemic stroke, and we further included the subtypes cardioembolic stroke, large artery stroke, and small vessel stroke.

\begin{tabular}{|c|c|c|c|c|c|}
\hline Outcome & Pleiotropic pathway & RSS 1 & RSS 2 & F-statistic & $\boldsymbol{p}$-value \\
\hline \multirow{2}{*}{$\begin{array}{c}\text { Any } \\
\text { ischemic } \\
\text { stroke }\end{array}$} & Smoking & 40.230 & 39.436 & 0.584 & 0.451 \\
\cline { 2 - 6 } & Body mass index & 40.230 & 36.919 & 2.601 & 0.118 \\
\cline { 2 - 6 } & C-reactive protein & 37.457 & 34.841 & 2.103 & 0.158 \\
\hline \multirow{2}{*}{$\begin{array}{c}\text { Cardio- } \\
\text { embolic }\end{array}$} & Smoking & 43.899 & 42.439 & 0.998 & 0.326 \\
\cline { 2 - 6 } stroke & Body mass index & 43.899 & 43.733 & 0.110 & 0.743 \\
\cline { 2 - 6 } & C-reactive protein & 42.765 & 37.544 & 3.894 & 0.058 \\
\hline \multirow{2}{*}{$\begin{array}{c}\text { Large } \\
\text { artery } \\
\text { stroke }\end{array}$} & Smoking & 41.290 & 40.612 & 0.483 & 0.492 \\
\cline { 2 - 6 } & Body mass index & 41.290 & 41.290 & 0.000 & 0.997 \\
\hline \multirow{3}{*}{$\begin{array}{c}\text { Small vessel } \\
\text { stroke }\end{array}$} & Body mass index & 26.742 & 23.993 & 3.322 & 0.079 \\
\cline { 2 - 6 } & C-reactive protein & 40.872 & 39.648 & 0.865 & 0.360 \\
\cline { 2 - 6 } & Smoking protein & 26.177 & 26.176 & 0.001 & 0.978 \\
\hline
\end{tabular}


Table S6: Mendelian randomization estimates from the inverse-variance weighted Mendelian randomization analysis considering different Covid-19 phenotypes as exposure for ischemic stroke subtypes. Covid-19 phenotypes were based on the definitions by the Covid-19 host genetics initiative. Mendelian randomization estimates represent the odds ratio for ischemic stroke outcomes per unit increase in the log-odds ratio of liability to the respective Covid-19 definition. In addition to the Mendelian randomization estimates, we included their 95\% confidence interval (CI) and corresponding $p$-value. Instrument selection was based on genetic variants that were associated with the respective Covid-19 definition with a $p$-value equal to or smaller than $5 \times 10^{-6}$. Moreover, we displayed heterogeneity measured by the Q-statistic and the corresponding heterogeneity $p$-value (Het. $p$-value). Main outcome was any ischemic stroke, and we further included the subtypes cardioembolic stroke, large artery stroke, and small vessel stroke.

\begin{tabular}{|c|c|c|c|c|c|c|c|}
\hline Exposure & Outcome & Estimate & $\begin{array}{l}95 \% \text { CI } \\
\text { Lower }\end{array}$ & $\begin{array}{l}95 \% \text { CI } \\
\text { Upper }\end{array}$ & $p$-value & $\begin{array}{c}\text { Q- } \\
\text { statistic }\end{array}$ & $\begin{array}{c}\text { Het. } \\
p \text {-value }\end{array}$ \\
\hline \multirow{4}{*}{$\begin{array}{l}\text { Hospitalized for } \\
\text { Covid-19 versus } \\
\text { controls with } \\
\text { laboratory- } \\
\text { confirmed Covid-19 }\end{array}$} & Any ischemic stroke & 1.054 & 1.012 & 1.099 & 0.011 & 5.311 & 0.915 \\
\hline & $\begin{array}{l}\text { Cardioembolic } \\
\text { stroke }\end{array}$ & 1.044 & 0.963 & 1.133 & 0.294 & 5.062 & 0.928 \\
\hline & Large artery stroke & 1.061 & 0.957 & 1.177 & 0.258 & 5.080 & 0.927 \\
\hline & Small vessel stroke & 1.219 & 1.107 & 1.342 & $5.5 \times 10^{-5}$ & 7.964 & 0.717 \\
\hline \multirow{4}{*}{$\begin{array}{l}\text { Hospitalized for } \\
\text { Covid-19 versus } \\
\text { population controls }\end{array}$} & Any ischemic stroke & 1.026 & 0.981 & 1.073 & 0.268 & 46.406 & 0.021 \\
\hline & $\begin{array}{l}\text { Cardioembolic } \\
\text { stroke }\end{array}$ & 1.090 & 0.991 & 1.198 & 0.078 & 56.523 & 0.002 \\
\hline & Large artery stroke & 1.081 & 0.978 & 1.194 & 0.128 & 37.369 & 0.137 \\
\hline & Small vessel stroke & 0.991 & 0.912 & 1.078 & 0.841 & 30.302 & 0.399 \\
\hline \multirow{4}{*}{$\begin{array}{l}\text { Reported Covid-19 } \\
\text { versus population } \\
\text { controls }\end{array}$} & Any ischemic stroke & 1.126 & 1.005 & 1.262 & 0.041 & 59.811 & $1.1 \times 10^{-4}$ \\
\hline & $\begin{array}{l}\text { Cardioembolic } \\
\text { stroke }\end{array}$ & 1.158 & 0.960 & 1.396 & 0.125 & 44.238 & 0.010 \\
\hline & Large artery stroke & 1.464 & 1.184 & 1.811 & $4.2 \times 10^{-4}$ & 33.982 & 0.108 \\
\hline & Small vessel stroke & 1.043 & 0.879 & 1.237 & 0.629 & 25.093 & 0.457 \\
\hline
\end{tabular}


Cross-trait linkage disequilibrium score regression:

Primary outcome ischemic stroke, and secondary outcomes coronary artery

disease, heart failure and atrial fibrillation, and genetic confounders (BMI, lifetime smoking index and CRP). FDR-corrected $p$-values $<0.05$ are taken forward.

Main Mendelian randomization analysis:

Exposure: Critical Covid-19 vs population Outcome: Ischemic stroke and subtypes Instrumental variables: Uncorrelated $\left(r^{2}<0.01\right)$ genetic variants associated at $p$-value $<5 \times 10^{-6}$ with the exposure Method: Two-sample inverse-variance weighted Mendelian randomization
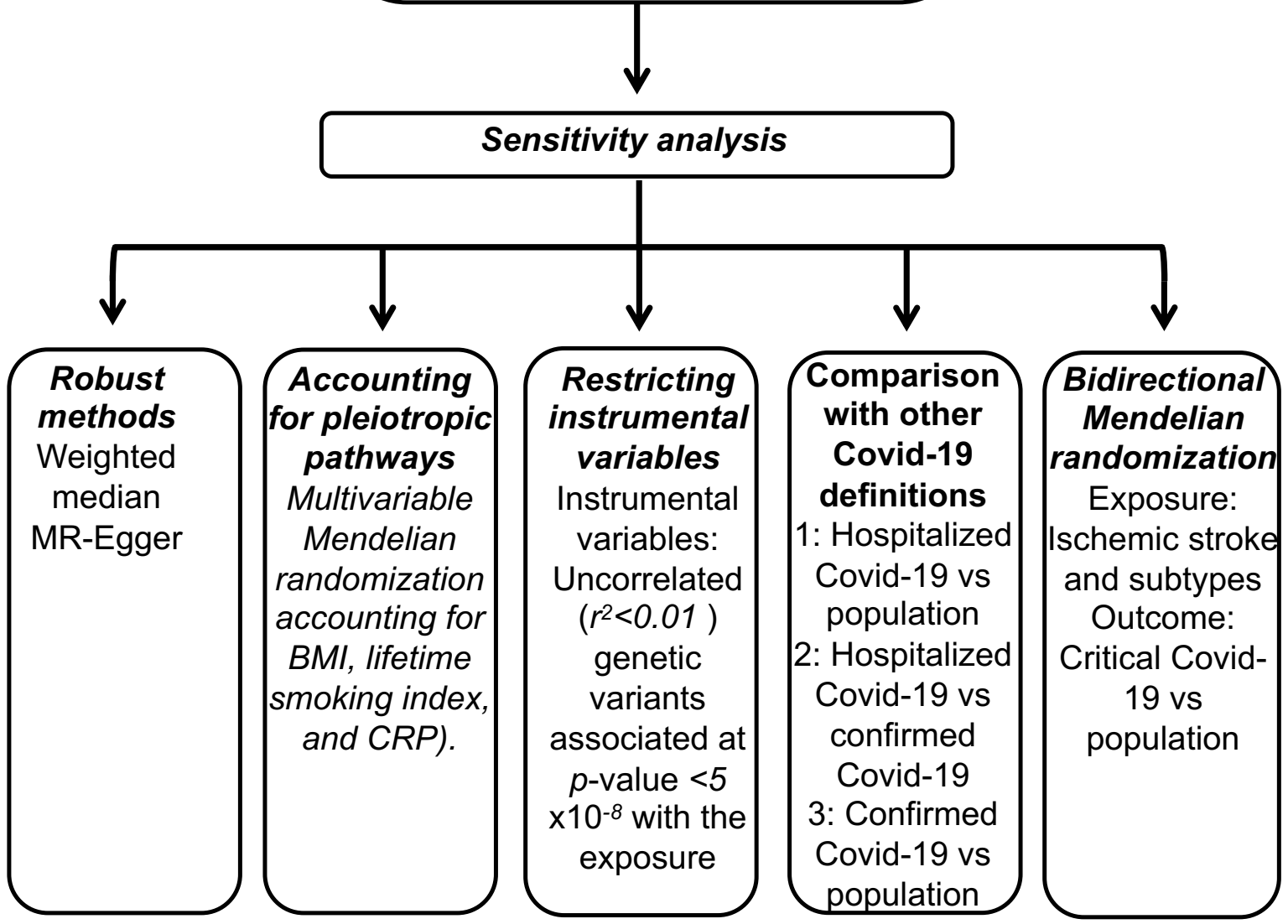

Figure S1: Illustration of the analytical plan. 


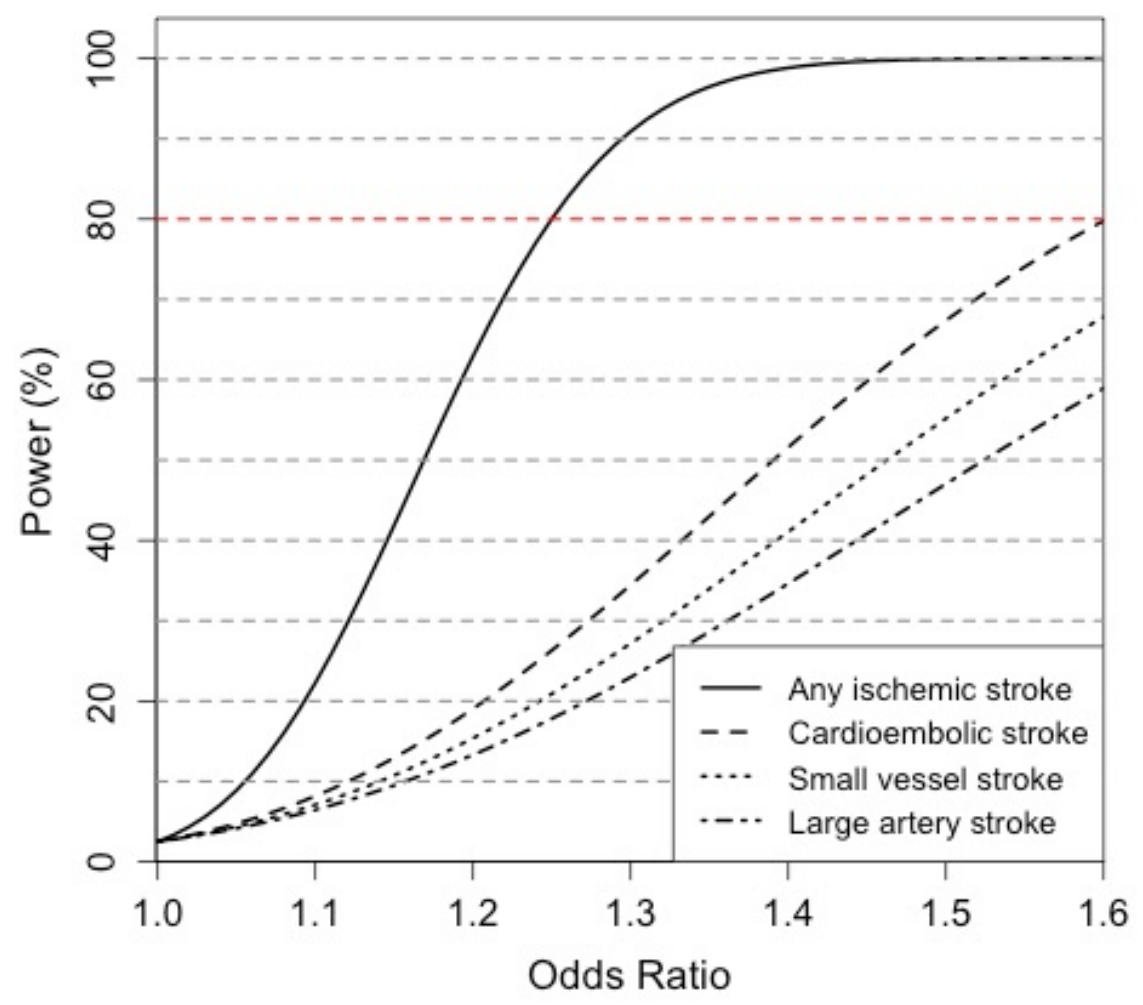

Figure S2: Power calculation showing power ( $y$-axis) as a function of Mendelian randomization estimates (odds ratio, $\mathrm{x}$-axis). Different line types describe different case and control numbers representing ischemic stroke and its subtype. See Table S 1 for the exact numbers of cases and control for each outcome. Note that the odds ratio is per one standard deviation unit increase in the exposure, which is not comparable to the Mendelian randomization odds ratios presented in the manuscript which are per unit increase in the log odds ratio of the exposure. 


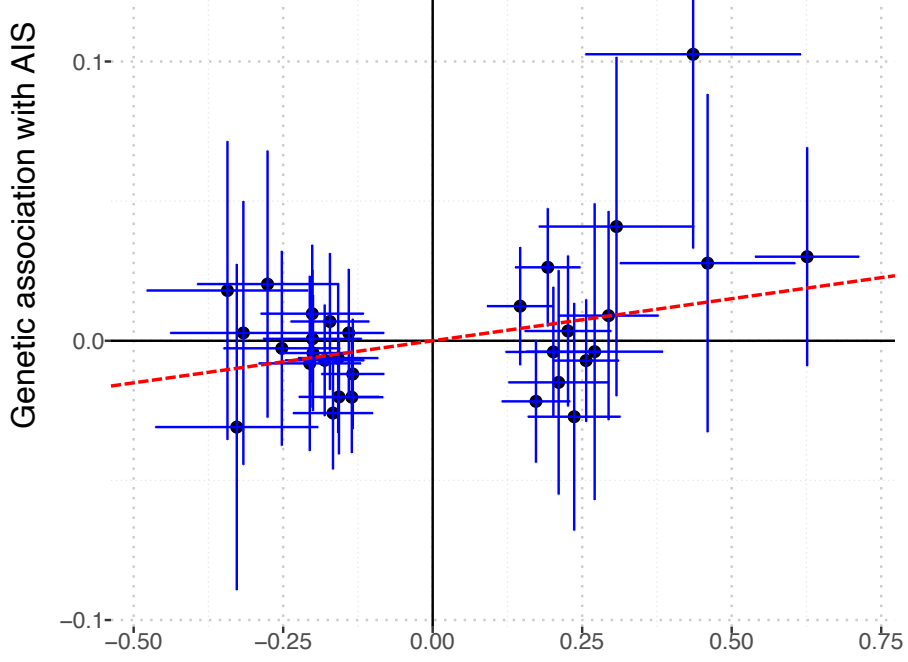

Genetic association with critical Covid-19

C

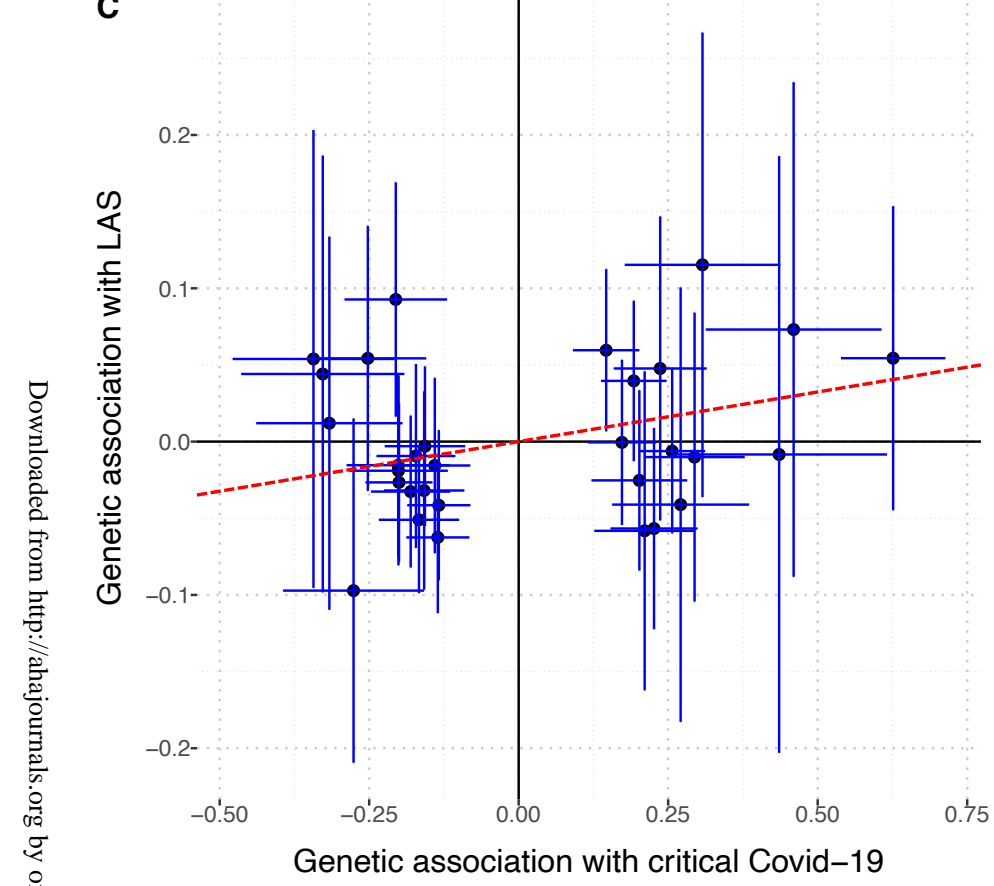

B

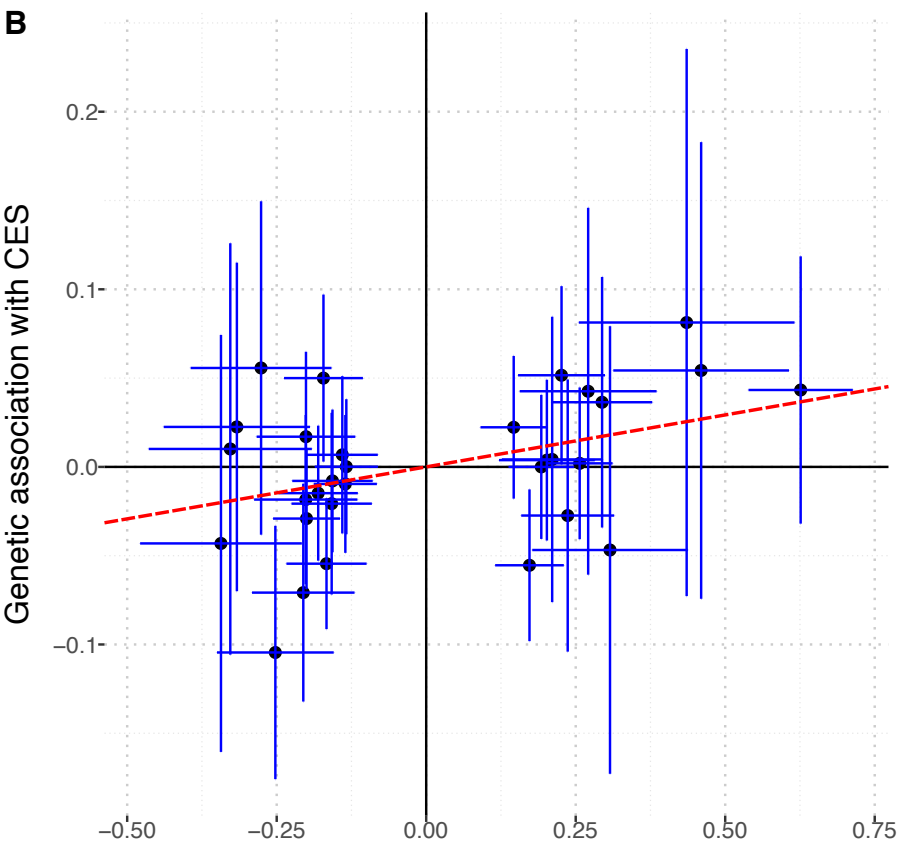

Genetic association with critical Covid-19

D $\quad 0.3-$

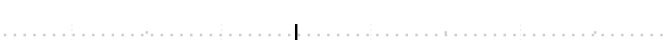

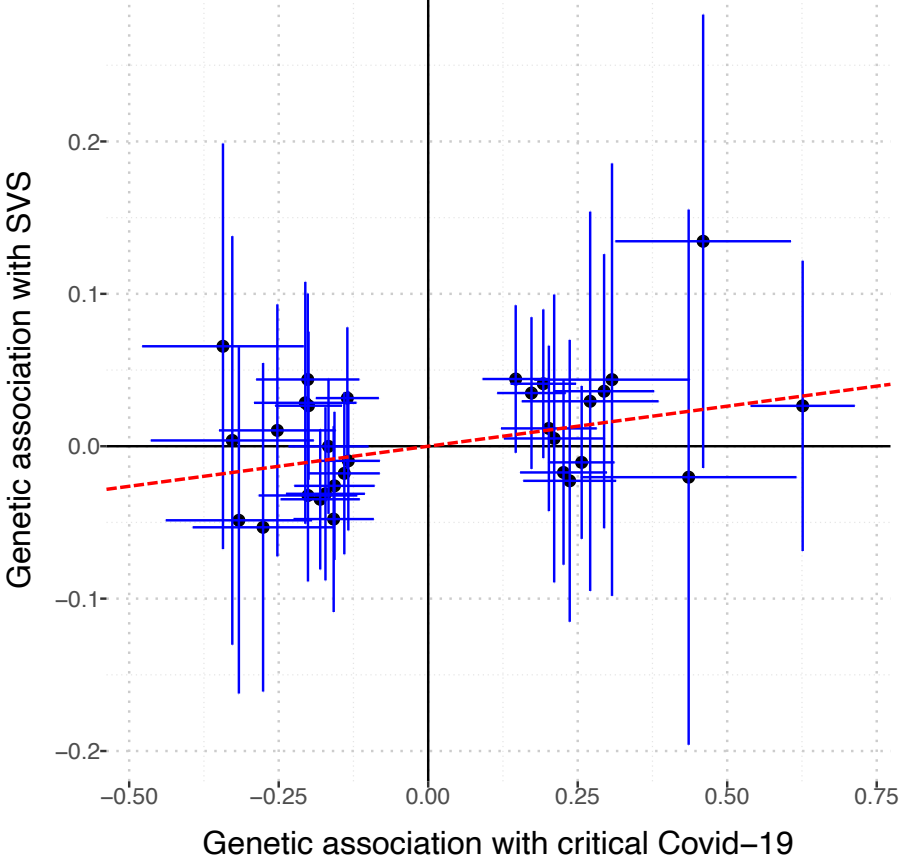

Figure S3: Scatterplots for diagnostics plot the genetic association of the 31 genetic variants used as instrumental variables with the exposure (liability to critical Covid-19) on the $x$-axis against genetic associations with the outcome (ischemic stroke phenotypes) on the $y$-axis. Error bars indicate the standard error of the genetic association. The inverse-variance weighted Mendelian randomization estimate is represented by the red dashed line through the origin. Each panel shows main outcome: Panel A) any ischemic stroke (AIS), B) cardioembolic stroke (CES), C) large artery stroke (LAS), and D) small vessel stroke (SVS), respectively. 


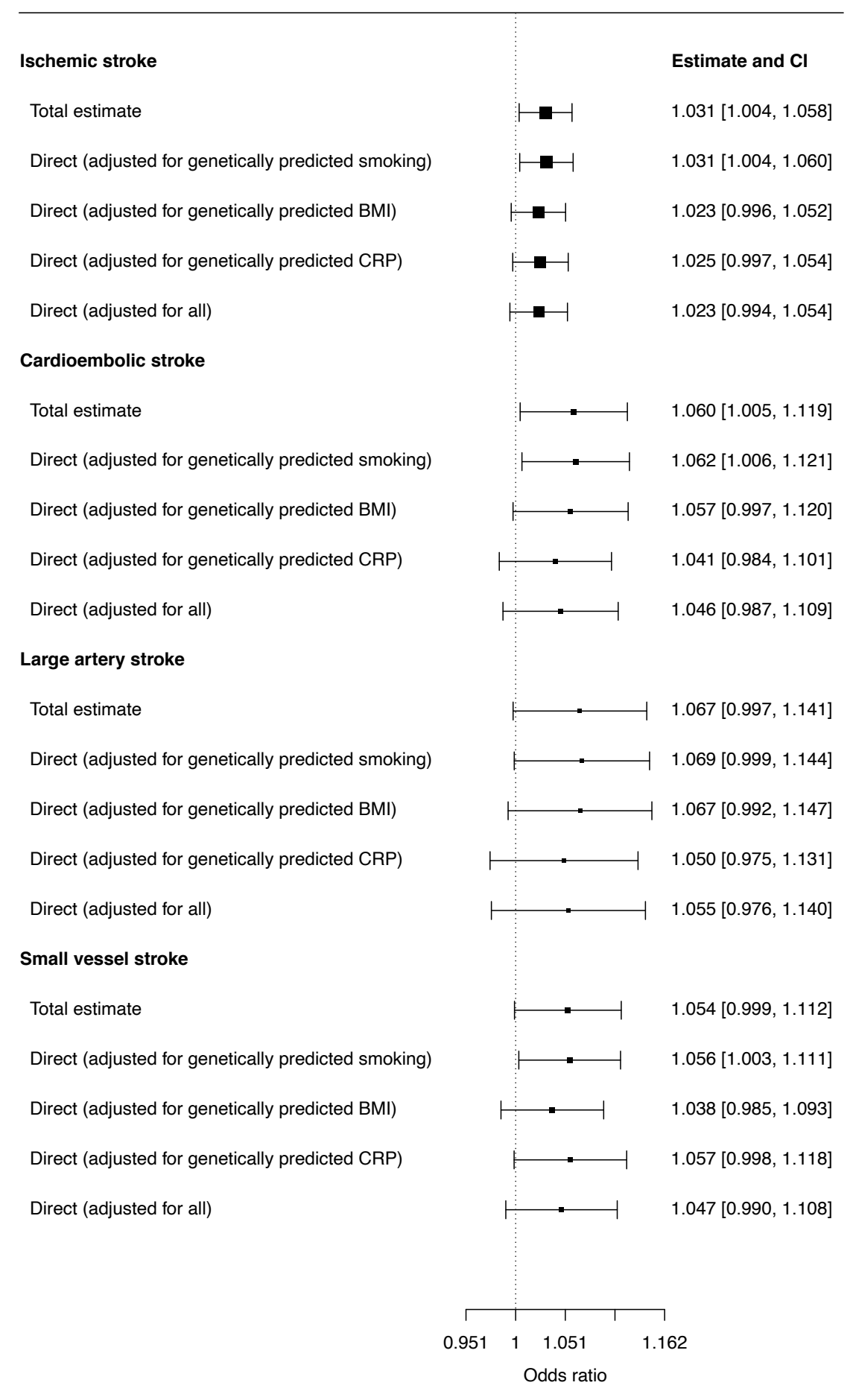

Figure S4: Forest plot contrasting the Mendelian randomization estimates and confidence intervals (CI) from univariable Mendelian randomization (total estimate) and multivariable Mendelian randomization accounting for potential pleiotropic pathways (direct estimate). The total estimate of liability to critical Covid-19 on ischemic stroke outcomes was derived from a univariable (unadjusted) Mendelian randomization model; the direct estimate of Covid19 on ischemic stroke outcomes was estimated in a multivariable Mendelian randomization model after adjusting for genetically predicted smoking intensity, body mass index (BMI), or C-reactive protein (CRP), and all three potential pleiotropic pathways jointly. Mendelian randomization estimates represent the odds ratio for ischemic stroke outcomes per unit increase in the log-odds ratio of liability to critical Covid-19. 


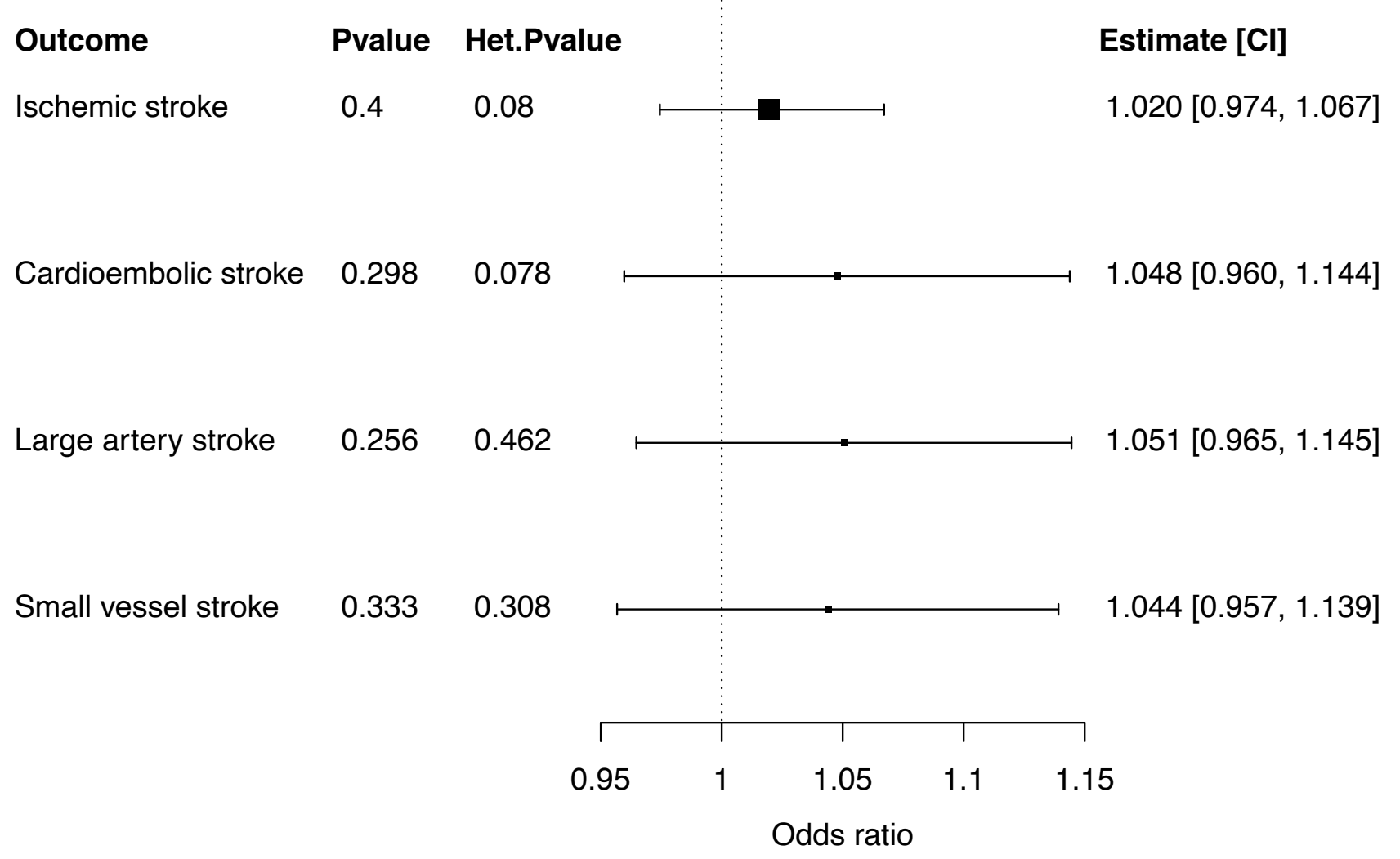

Figure S5: Forest plot illustrating the Mendelian randomization estimates of liability to critical Covid-19 on stroke outcomes based on inverse-variance weighted Mendelian randomization using 9 genetic variants which were associated with liability to critical Covid-19 at genome-wide significance $\left(p\right.$-value $\left.<5 \times 10^{-8}\right)$. Mendelian randomization estimates represent the odds ratio for ischemic stroke outcomes per unit increase in the logodds ratio of critical Covid-19 liability. Additional columns include the $p$-value ( $p$-value) of the Mendelian randomization estimate to be different from the null, represented by a dashed line at an odds ratio of 1 , and the heterogeneity of the Mendelian randomization model measured by the heterogeneity $p$-value (Het. $p$-value) as well as the Mendelian randomization estimate and its 95\% confidence interval (CI). 


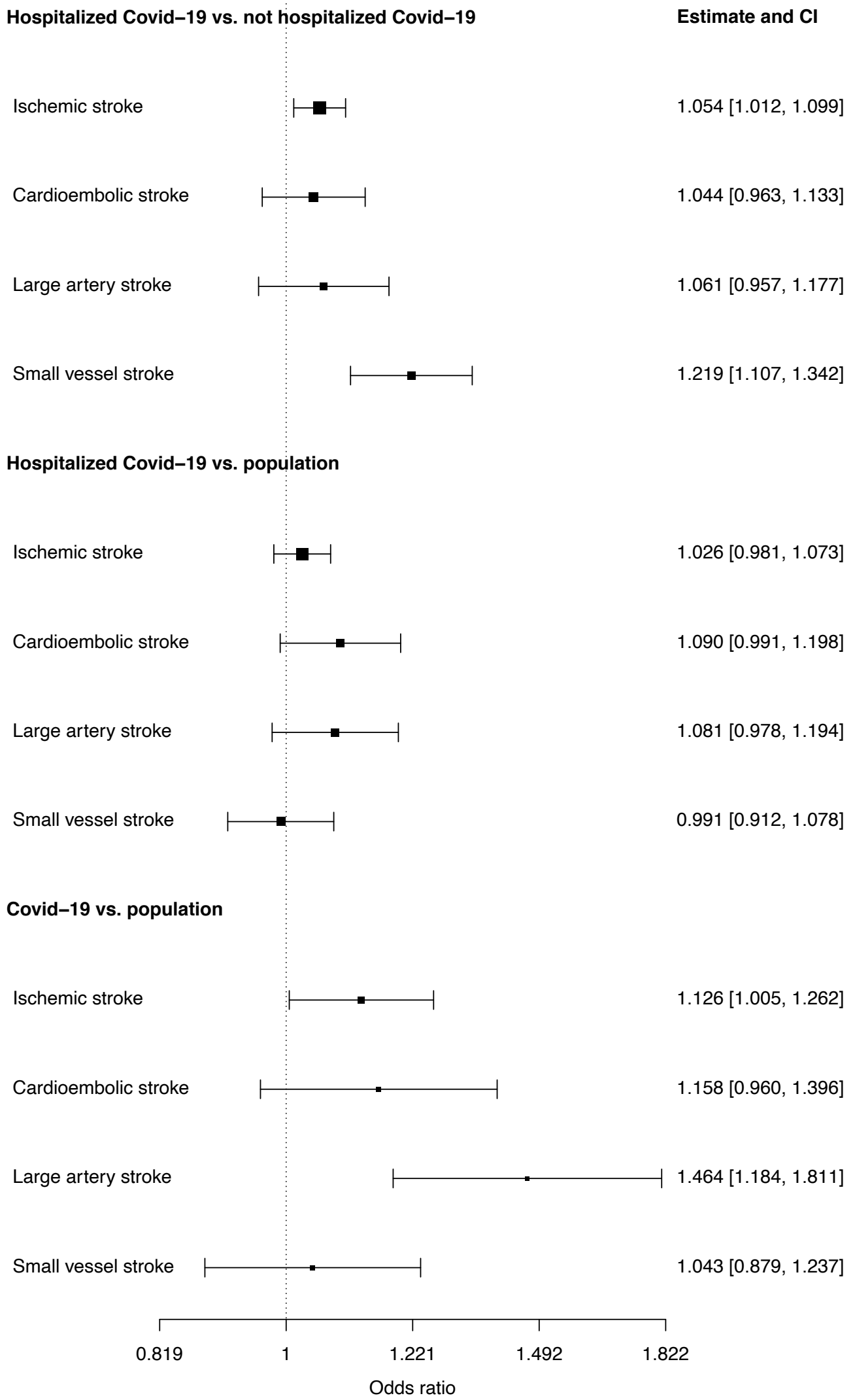

Figure S6: Forest plot illustrating the inverse-variance weighted Mendelian randomization estimate and 95\% confidence interval (CI) considering Covid-19 phenotypes as exposure for ischemic stroke outcomes. Covid-19 phenotypes were based on the definitions by the Covid-19 host genetics initiative. Mendelian randomization estimates represent the odds ratio for ischemic stroke outcomes per unit increase in the log-odds ratio of liability to the respective Covid-19 definition. Genetic variants which were associated with the Covid-19 definition were selected as instrumental variables at a $p$-value level equal to $5 \times 10^{-6}$ or smaller. 